\title{
Seismic Response of a Bridge Pile Foundation during a Shaking Table Test
}

\author{
Yunxiu Dong $\mathbb{D}^{1,2}$ Zhongju Feng, ${ }^{1}$ Jingbin He ${ }^{1},{ }^{1}$ Huiyun Chen, ${ }^{1}$ Guan Jiang, \\ and Honghua Yin ${ }^{3}$
}

\author{
${ }^{1}$ Highway School, Chang'an University, Xi'an, Shaanxi 710064, China \\ ${ }^{2}$ School of Civil Engineering, Longdong University, Qingyang, Gansu 745000, China \\ ${ }^{3}$ Jinan Highway Administration, Jinan, Shandong 250000, China
}

Correspondence should be addressed to Yunxiu Dong; dongyunxiu_0524@163.com

Received 17 July 2019; Revised 23 October 2019; Accepted 29 October 2019; Published 26 November 2019

Academic Editor: Vadim V. Silberschmidt

Copyright ( 2019 Yunxiu Dong et al. This is an open access article distributed under the Creative Commons Attribution License, which permits unrestricted use, distribution, and reproduction in any medium, provided the original work is properly cited.

Puqian Bridge is located in a quake-prone area in an 8-degree seismic fortification intensity zone, and the design of the peak ground motion is the highest grade worldwide. Nevertheless, the seismic design of the pile foundation has not been evaluated with regard to earthquake damage and the seismic issues of the pile foundation are particularly noticeable. We conducted a large-scale shaking table test (STT) to determine the dynamic characteristic of the bridge pile foundation. An artificial mass model was used to determine the mechanism of the bridge pile-soil interaction, and the peak ground acceleration range of $0.15 \mathrm{~g}-0.60 \mathrm{~g}$ ( $\mathrm{g}$ is gravity acceleration) was selected as the input seismic intensity. The results indicated that the peak acceleration decreased from the top to the bottom of the bridge pile and the acceleration amplification factor decreased with the increase in seismic intensity. When the seismic intensity is greater than $0.50 \mathrm{~g}$, the acceleration amplification factor at the top of the pile stabilizes at 1.32 . The bedrock surface had a relatively small influence on the amplification of the seismic wave, whereas the overburden had a marked influence on the amplification of the seismic wave and filtering effect. Damage to the pile foundation was observed at $0.50 \mathrm{~g}$ seismic intensity. When the seismic intensity was greater than $0.50 \mathrm{~g}$, the fundamental frequency of the pile foundation decreased slowly and tended to stabilize at $0.87 \mathrm{~Hz}$. The bending moment was larger at the junction of the pile and cap, the soft-hard soil interface, and the bedrock surface, where cracks easily occurred. These positions should be focused on during the design of pile foundations in meizoseismal areas.

\section{Introduction}

Earthquakes are natural disasters with great destructive power. Considerable damage to pile-supported bridges has been observed in many earthquakes worldwide, especially in China, where nearly $50 \%$ of the land is located in seismic fortification intensity zones that exceed 7 degrees; the earthquake intensity zoning map of China is shown in Figure 1. In recent decades, large-span bridges with high bearing capacity and excellent seismic performance have been designed for use in meizoseismal areas, but the damage has occurred to these bridges. Seismic damages include not only the failure of the upper structure, such as girder failure, support failure, and bridge pier slip but also the occurrence of concrete cracks and ring cracks of the pile and even complete failure after earthquakes, which are shown in Figure 2 [1]. Once the pile foundation is damaged, the entire bridge poses a safety risk.

The mechanical behavior of pile foundations subjected to kinetic forces has been investigated experimentally and numerically by many researchers. Mylonakis et al. [2] proposed a substructuring method for the seismic analysis of bridge piers supported on vertical piles and pile groups in multilayered soil. Haeri et al. [3] studied the response of a group of piles subjected to liquefaction-induced lateral spreading caused by liquefaction by using large $1 \mathrm{~g}$ shaking table test and proposed a simple numerical method to predict the behavior of single piles under lateral spreading. Montejo et al. [4], Mostafa and Naggar [5], and Naggar and Gazetas [6] proposed a seismic deformation method (SDM) 


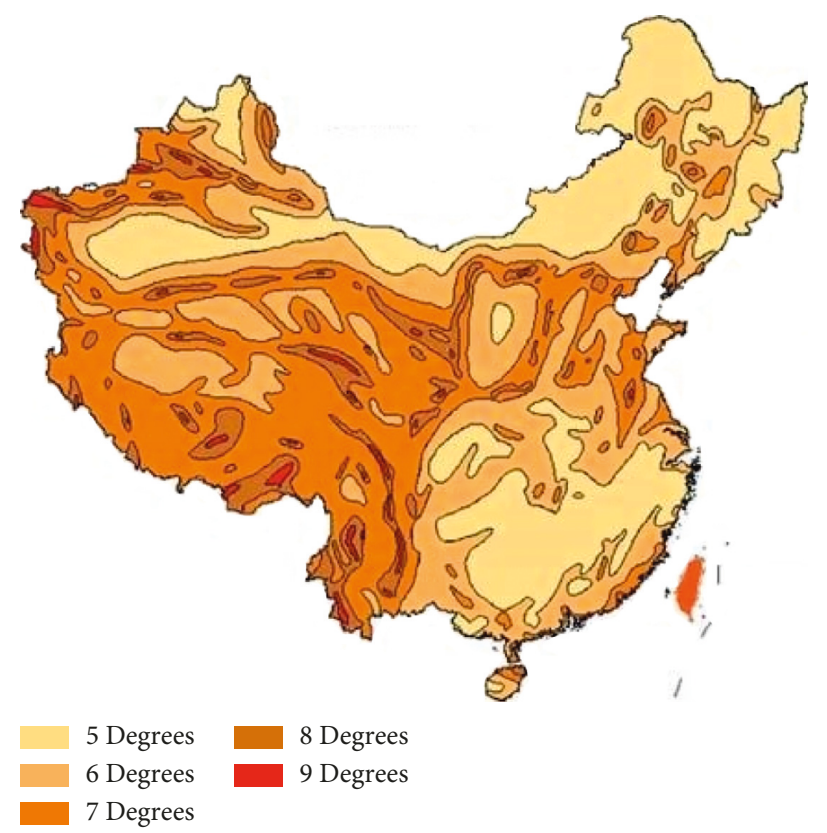

Figure 1: Earthquake intensity zoning map of China.

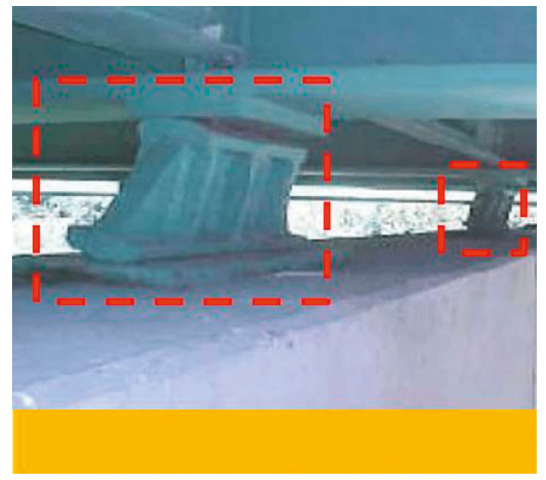

(a)

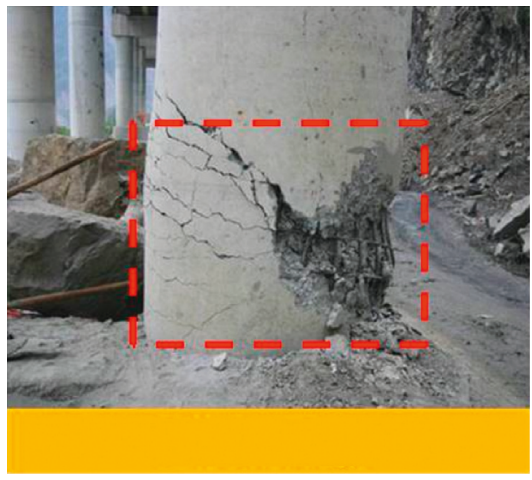

(b)

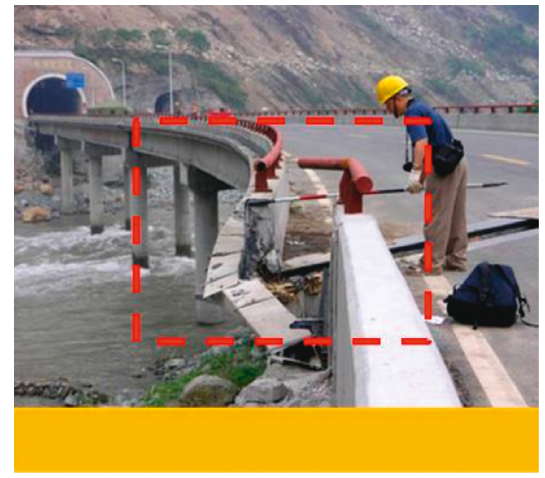

(c)

Figure 2: Seismic damage of bridge: (a) support failure; (b) pile breakage; (c) bridge pier slip.

to assess the seismic performance of pile foundation of buildings based on the inertial interaction between the pile, the soil, and the structure. Boulanger et al. [7] evaluated the dynamic beam on a nonlinear Winkler foundation analysis method for analysing seismic soil-pile-structure interaction based on a series of dynamic centrifuge model test results. A seismic evaluation of pile foundations was conducted using three different methods based on a 3D elastic-plastic finite element analysis [8, 9]. Di Laora and Rovithis [10] investigated the dynamic characteristics of the pile by simplifying the Winkler foundation beam model and putting forward the concept of the effective length of the pile foundation and conducted a theoretical calculation of the liquefaction at the site. A shaking table test (STT) is commonly used to study the characteristics of piles embedded into different types of soil. Suzuki et al. [11] conducted a large-scale STT to investigate the factors influencing the stress distributions of pile groups during earthquakes in dry sand. Dungca et al. [12], Yao et al. [13], and Motamed and Towhata [14] conducted an STT to study the dynamic behavior of pile foundations during liquefacation. Shirato et al. [15] and Ecemis [16] conducted a large-scale STT and numerical simulation on the nonlinear behavior of pile groups subjected to lateral loading during a very large earthquake. Most researchers have mainly focused on the dynamic response during soil liquefaction and soft soil foundation [17-24]. However, few studies have been conducted on the response characteristics of a bridge rock-socketed pile foundation for different seismic intensities. Therefore, it is essential to research the seismic response characteristics of a large-diameter rock-socketed pile foundation.

In this study, an artificial mass model was used to determine the dynamic response of rock-socketed pile foundations for a seismic intensity range of $0.15 \mathrm{~g}-0.60 \mathrm{~g}$ using a large-scale STT and the inertial soil-pile interaction mechanisms were investigated. The results of this research provide 
guidance and technical support for engineers who work in practice.

\section{General Project Information}

The Puqian Bridge, which crosses Puqian Bay in the northeast of Hainan province in China, is a bridge linking Wenchang City with Haikou City. The bridge site is located at the epicenter of the Qiongshan earthquake that occurred in 1605 and had a Richter magnitude of 7.5. The area is seismically active with multiple faults and active faults and is the site of frequent earthquakes. The seismic fortification intensity of the bridge site is 8 degrees, and the peak ground acceleration that has a $10 \%(2 \%)$ probability of being exceeded in 50 years is $0.35 \mathrm{~g}(0.59 \mathrm{~g})$. The peak ground acceleration exceeds the upper limit of the acceleration response spectrum of the horizontal design for a bridge provided in Section 5.2.2 of the Specification of Seismic Design for Highway Engineering (JTG B02-2013) [25]. The potential damage to the pile foundation as a result of seismic events is relatively high.

Four piles of reinforced concrete (RC) with a cap numbered 38\# were selected as prototype piles; the details were as follows: the piles were end-bearing piles, $2.4 \mathrm{~m}$ in diameter, $54 \mathrm{~m}$ in length, the pile spacing was $5.5 \mathrm{~m}$, and the cap dimension was $9.2 \mathrm{~m}$ (length) $\times 9.2 \mathrm{~m}$ (width) $\times 3.0 \mathrm{~m}$ (height). The soil layers at the pile site from top to bottom were $14 \mathrm{~m}$ of mucky clay, $10 \mathrm{~m}$ of coarse sand, $22 \mathrm{~m}$ of gravelly soil, and $6 \mathrm{~m}$ of lightly weathered granite.

\section{Shaking Table Test}

This study was conducted using shake table facility of the earthquake engineering and engineering vibration laboratory at the Institute of Engineering Mechanics (IEM), China Earthquake Administration. IEM shaking table is a $5 \mathrm{~m} \times 5 \mathrm{~m}$, 3DOFS facility, capable of taking vertical loads up to $300 \mathrm{kN}$. The maximum horizontal acceleration of the shaking table was $1.0 \mathrm{~g}$, the maximum vertical acceleration was $0.7 \mathrm{~g}$, and the vibration frequency ranged from $0.1 \mathrm{~Hz}$ to $50 \mathrm{~Hz}$.

3.1. Model Box. Considering the operability of the STT, a laminate shear model box was used to investigate the dynamic response of the pile foundation. The dimension of the box was $3.7 \mathrm{~m}$ (length) $\times 2.8 \mathrm{~m}$ (width) $\times 2.0 \mathrm{~m}$ (height), as shown in Figure 3. The seismic response of the free field was simulated by using a shaking table to reduce the error of peak acceleration of the soil layer, the waveform, and the Fourier amplitude spectrum. Boundary condition in this study is of low degree of importance. When the length of the laminate shear model box is no less than $2 \mathrm{~m}$ and the width is no less than $1.5 \mathrm{~m}$, the frequency deviation in the STT is $\pm 5 \%$ and the influence of the height of the box can be ignored [26].

3.2. Scaling Factors. The test materials were selected from the prototype materials used in the actual construction of the

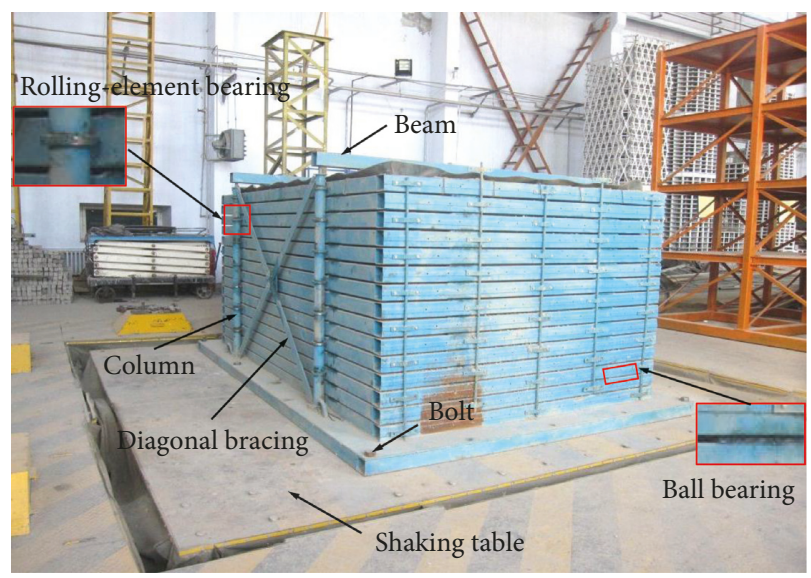

Figure 3: Laminate shear model box.

Puqian Bridge. The key parameter to characterize the reliability of the results of the STT is the dynamic similarity between the parameters of the model and the prototype. In this study, all required material properties of the physical model were scaled using similitude law suggested by Iai et al. [27]. Structures are usually scaled down to a smaller size $[28,29]$. Considering the dimensions of the laminate shear model box, a geometric scale of $\lambda=30$ was used. Based on the actual bearing capacity of the vibrating table and the similar conditions of the artificial mass $[30,31]$, the required payload capacity was $100 \mathrm{~kg}$. Table 1 summarizes the scaling factors applied in this study.

3.3. Model Piles. Figure 4 shows the schematic cross section of the physical model along with the general layout of transducers. As seen in this figure, the physical model consists of four piles with a cap. Before the soil stratum was constructed, the piles were connected to the base to achieve a fixed base condition. The material of the model piles and cap was concrete $\mathrm{C} 35$ and the reinforcement ratio of the model pile was 2.4\%; a steel bar (HPB235 type) with a diameter of $4 \mathrm{~mm}$ was used. The physical parameters of the pile are listed in Table 2, and the model pile is shown in Figure 5.

The model was instrumented with sensors on the pile such as strain gauges, accelerometers, and a displacement gauge. Among them, strain gauges were attached to the pile to measure the bending strain. In this test, 18 strain gauges are evenly arranged on the left and right sides of the pile, mainly at the interface between the middle of each soil layer and the soil interfacial. 5 accelerometers are located on the side of the pile, mainly at the interface between the middle of each soil layer and the soil interfacial. A displacement meter is arranged at the top of the pile. In total, 24 channels of data were recorded during this test.

3.4. Physical Properties of Soil Layer. The ground in the model consisted of a $47 \mathrm{~cm}$ thick mucky clay layer, a $33 \mathrm{~cm}$ thick coarse sand layer, and a $73 \mathrm{~cm}$ thick pebble layer, overlying a $40 \mathrm{~cm}$ bedrock. Based on the geological survey data of the bridge, the shear wave velocities of the soil layers were determined to ensure the similarity between the actual 
TABLE 1: Scaling factors for $1 \mathrm{~g}$ shaking table test.

\begin{tabular}{lcc}
\hline Parameter & $\begin{array}{c}\text { Scaling factors proposed by Iai et al. [27] (prototype/ } \\
\text { model) }\end{array}$ & Scaling factors in this study (prototype/model) \\
\hline Length $(l)$ & $\lambda$ & 30 \\
Density $(\rho)$ & $\lambda_{\rho}$ & 1.0 \\
Strain $(\varepsilon)$ & $\lambda_{\varepsilon}$ & 1.0 \\
Elasticity $(E)$ & $\lambda_{E}$ & 1.0 \\
Time $(t)$ & $\left(\lambda \lambda_{\varepsilon}\right)^{0.5}$ & $\sqrt{30}$ \\
Acceleration $(a)$ & 1.0 & 1.0 \\
Displacement $(\delta)$ & $\lambda \lambda_{\varepsilon}$ & 30 \\
Stress $(\sigma)$ & $\lambda \lambda_{\rho}$ & 30 \\
Velocity $(v)$ & $\left(\lambda \lambda_{\varepsilon}\right)^{0.5}$ & $\sqrt{30}$ \\
\hline
\end{tabular}

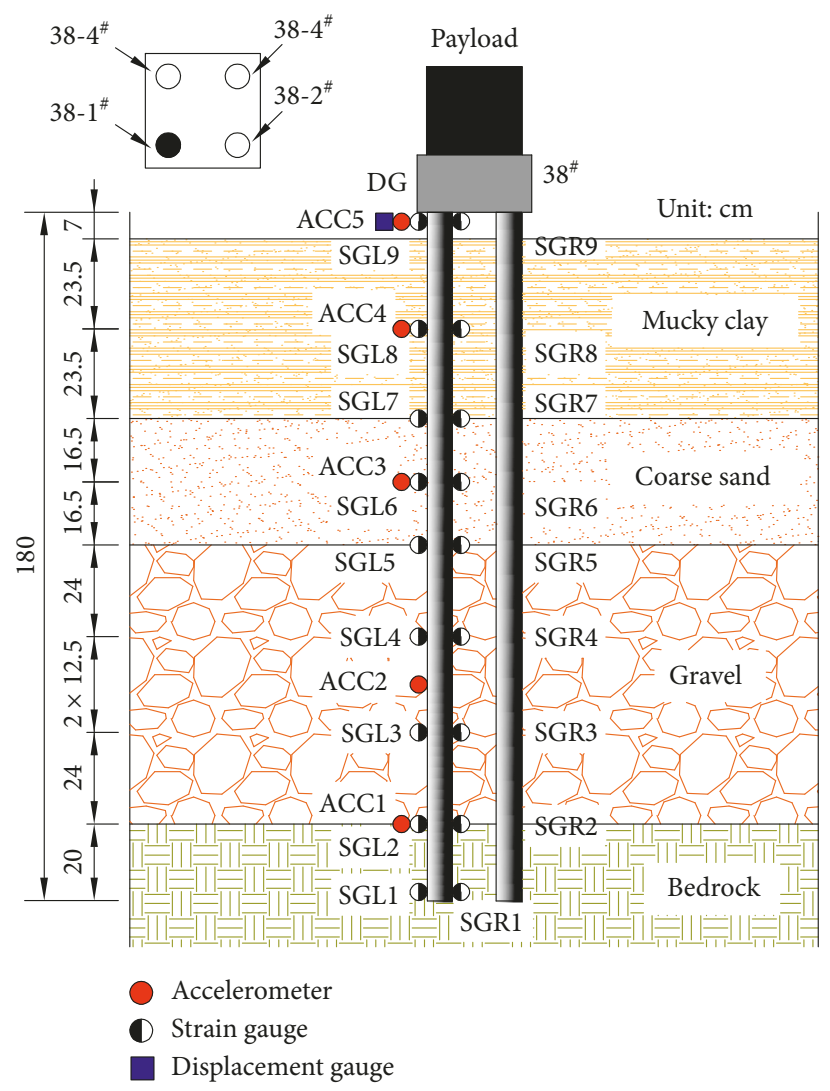

Figure 4: Cross section of the physical model and location of installed instruments.

TABLe 2: Parameters of model pile.

\begin{tabular}{lccccc}
\hline Concrete & Pile length & Pile diameter & Bar diameter & Reinforcement ratio & Young's modulus $E$ \\
\hline C35 & $180 \mathrm{~cm}$ & $8 \mathrm{~cm}$ & $0.4 \mathrm{~cm}$ & $2.4 \%$ & $31.5 \mathrm{GPa}$ \\
\hline
\end{tabular}

soil and the soil used in the test. The parameters are listed in Table 3.

The shear wave velocity of the model soil is controlled by the shear wave velocity method to make it consistent with the shear wave velocity of the prototype soil. The method is to place an accelerometer in the lower part of the closed container, and then fill the test soil into the closed container. By lifting the tamping hammer to a fixed height of $30 \mathrm{~cm}$, the accelerometer is placed on the top of the model soil after the fixed number of compaction, as shown in Figure 6. Hit the bottom of the closed container with an iron rod; two accelerometers were used to collect the acceleration response at the same time, and the shear wave velocity of model soil was measured by the following equation

$$
v=\frac{\Delta h}{\Delta t}
$$

where $\Delta t$ is the time difference between the peak acceleration of vibration wave propagating from the bottom of the soil layer to the top of the soil layer and $\Delta h$ is the distance of 


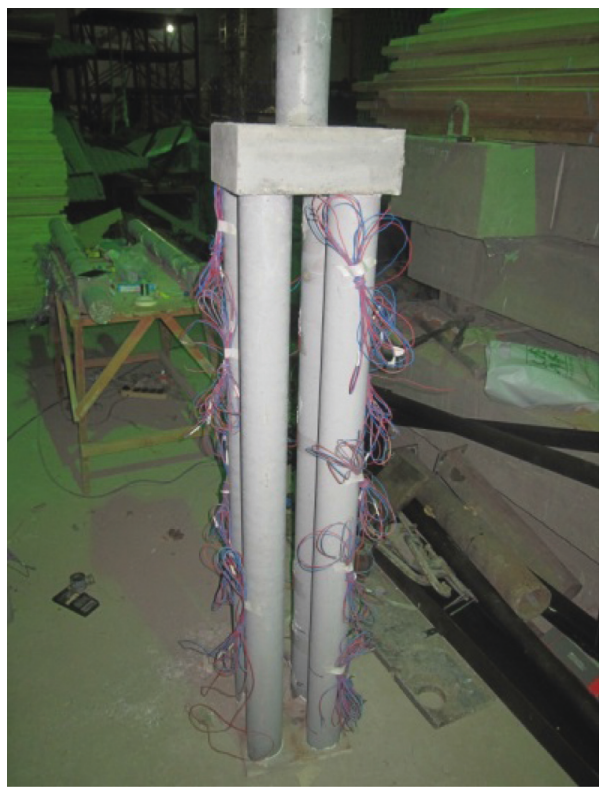

FIgure 5: Model pile.

TABLE 3: Shear wave velocities of the soil layers (unit: $\mathrm{m} \cdot \mathrm{s}^{-1}$ ).

\begin{tabular}{lcccc}
\hline Soil layer & Mucky clay & Coarse sand & Gravel & Slightly weathered granite \\
\hline Wave velocity & 138 & 212 & 539 & 917 \\
\hline
\end{tabular}

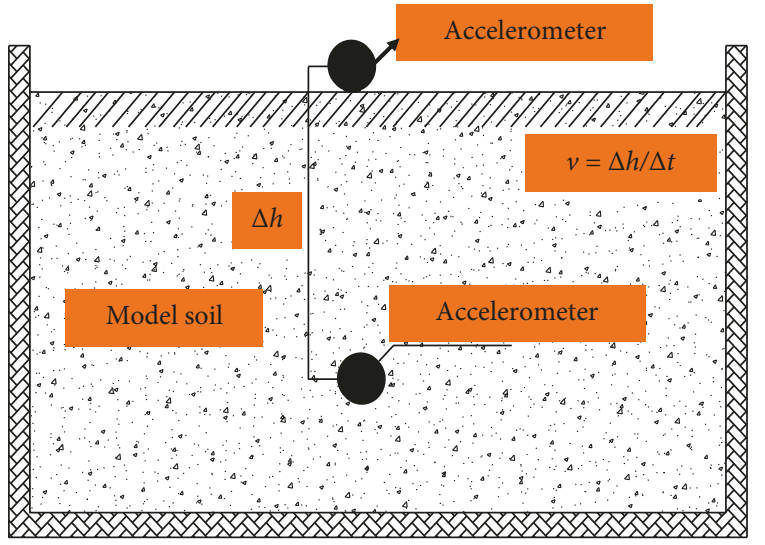

(a)

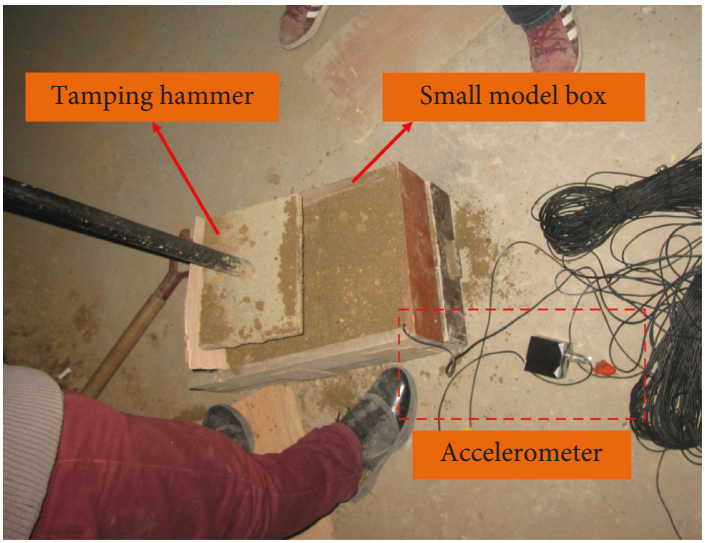

(b)

FIGURE 6: Shear wave velocity method: (a) sketch map and (b) specific implementation.

vibration wave propagating in rock and soil, that is, the height of soil in the model box.

After reaching the controlled number of compaction, the direct shear test and compression test of the model soil samples from the model box are carried out and the parameters of the model soil are obtained as shown in the Table 3. The parameters of the model soil are determined and prepared in the shaking table test as shown in Table 4 and Figure 7.

The bedrock of the rock-socketed pile in the prototype belongs to the slightly weathered granite. In the model test, the bedrock material is C50 concrete with an average compressive strength of $50 \mathrm{MPa}$. When making bedrock, the PVC pipe with $8 \mathrm{~cm}$ outside diameter is used to reserve $20 \mathrm{~cm}$ deep holes in the predefined position of the model pile to ensure that the model pile can be fully embedded in the holes reserved by the bedrock model, as shown in Figures 8 and 9.

3.5. Seismic Wave. According to the Seismic Safety Evaluation Report of Puqian Bridge Project Site in Hainan Province compiled by the Institute of Geophysics, China Earthquake Administration, "5010-wave" (10\% probability 
TABLe 4: Model soil parameters.

\begin{tabular}{lcccccc}
\hline Soil layer & $\begin{array}{c}\text { Density }(\mathrm{g} / \\
\left.\mathrm{cm}^{3}\right)\end{array}$ & $\begin{array}{c}\text { Moisture content } \\
(\%)\end{array}$ & $\begin{array}{c}\text { Compression modulus } \\
(\mathrm{MPa})\end{array}$ & $\begin{array}{c}\text { Void } \\
\text { ratio }\end{array}$ & $\begin{array}{c}\text { Cohesion } \\
(\mathrm{kPa})\end{array}$ & \begin{tabular}{c} 
Internal friction angle $\left({ }^{\circ}\right)$ \\
\hline Mucky clay
\end{tabular} \\
\hline Coarse & 1.73 & 46.1 & 3.30 & 1.28 & 8.5 & 6 \\
sand & 1.89 & 16.1 & 4.05 & 0.62 & - & - \\
Gravel & 1.94 & 23.2 & 4.68 & 0.68 & - & - \\
\hline
\end{tabular}

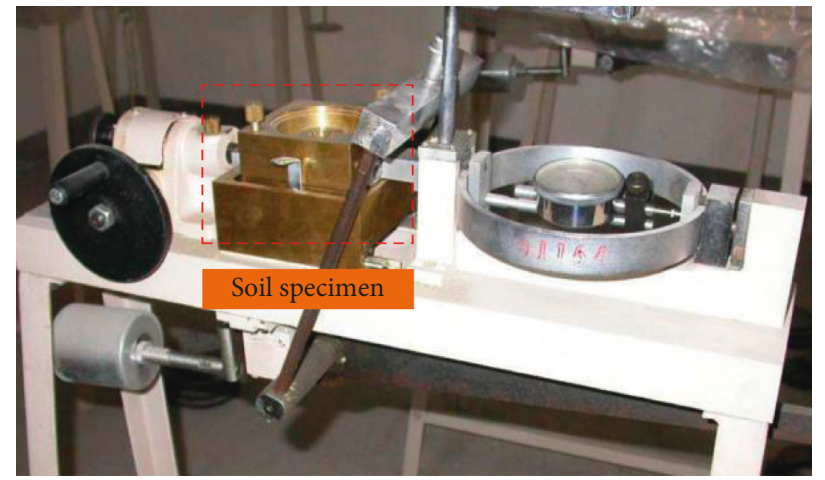

(a)

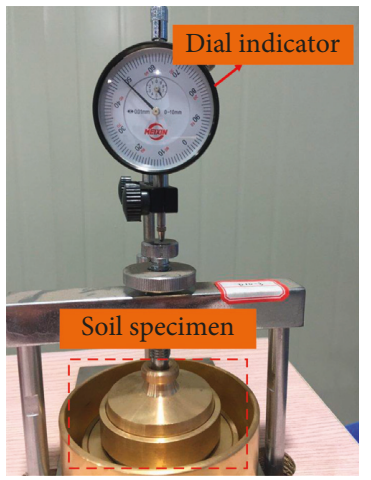

(b)

FIGURE 7: Tests: (a) direct shear test and (b) oedometer test.

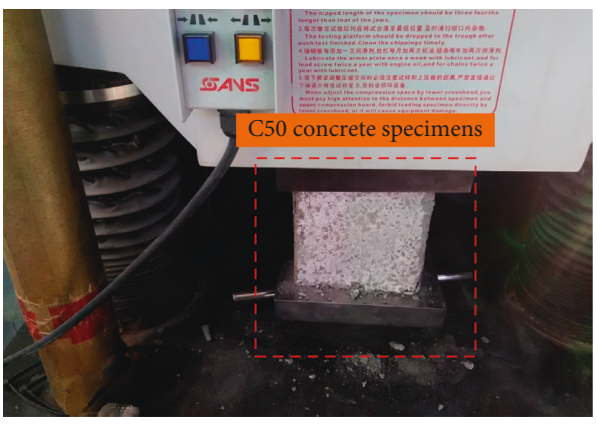

Figure 8: Compressive strength test of model bedrock.

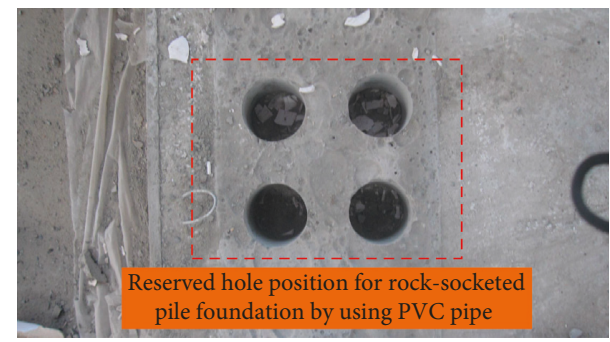

Figure 9: Preparation of model bedrock.

of exceedance in 50 years) was selected as the ground motion in the STT. The matching software SEISMOSIGNAL was used to filter and calibrate the seismic wave. The seismic wave was scaled down to ensure that its peak value was in the range of $0.15 \mathrm{~g}$ to $0.60 \mathrm{~g}$ with an increment of $0.05 \mathrm{~g}$ in a constant waveform. Figure 10 shows the $0.35 \mathrm{~g}$ seismic wave.

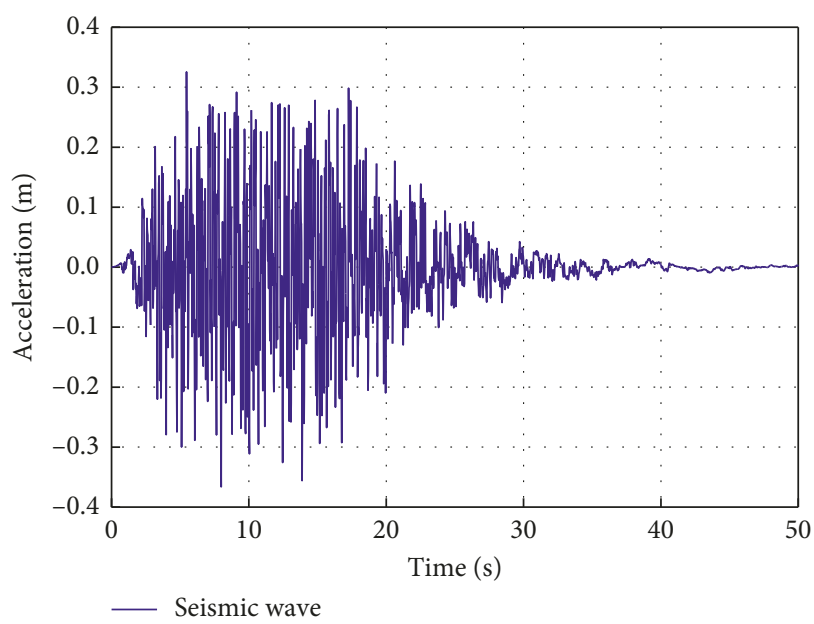

Figure 10: The $0.35 \mathrm{~g}$ seismic wave.

\section{Results and Discussions}

4.1. Pile Acceleration Response. The distribution of the maximum acceleration and amplification factor of pile along the length for different seismic intensities are shown in Figure 11. The acceleration amplification factor $\alpha$ (shown in equation (2)) is the ratio of the maximum acceleration of pile $\left(a_{\text {pile max }}\right)$ and the input maximum acceleration $\left(a_{\text {input max }}\right)$ :

$$
\alpha=\frac{a_{\text {pile max }}}{a_{\text {input max }}} .
$$

As can be seen from Figure 11, the distribution of the maximum acceleration and amplification factor along the 


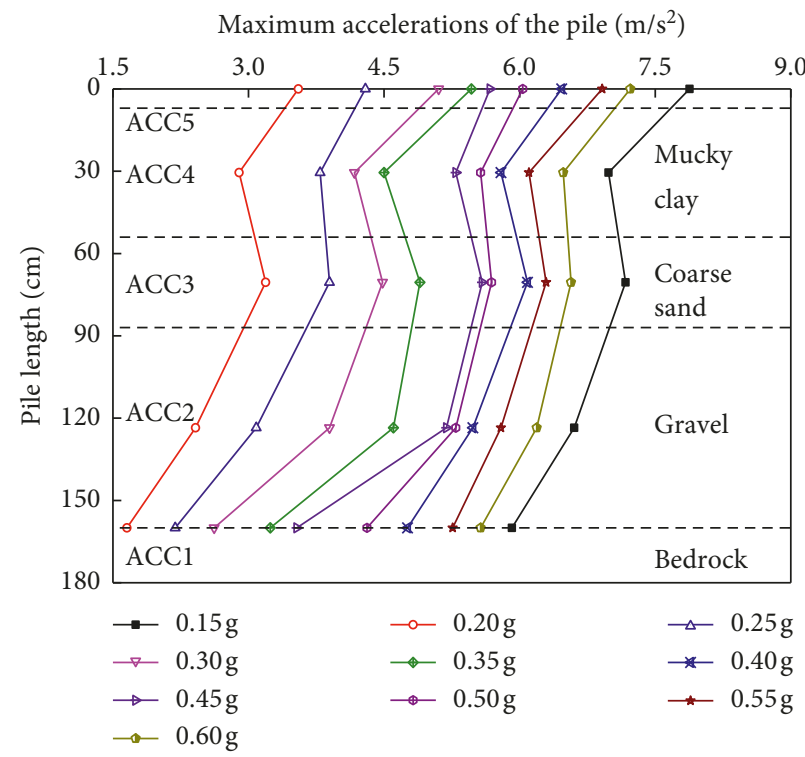

(a)

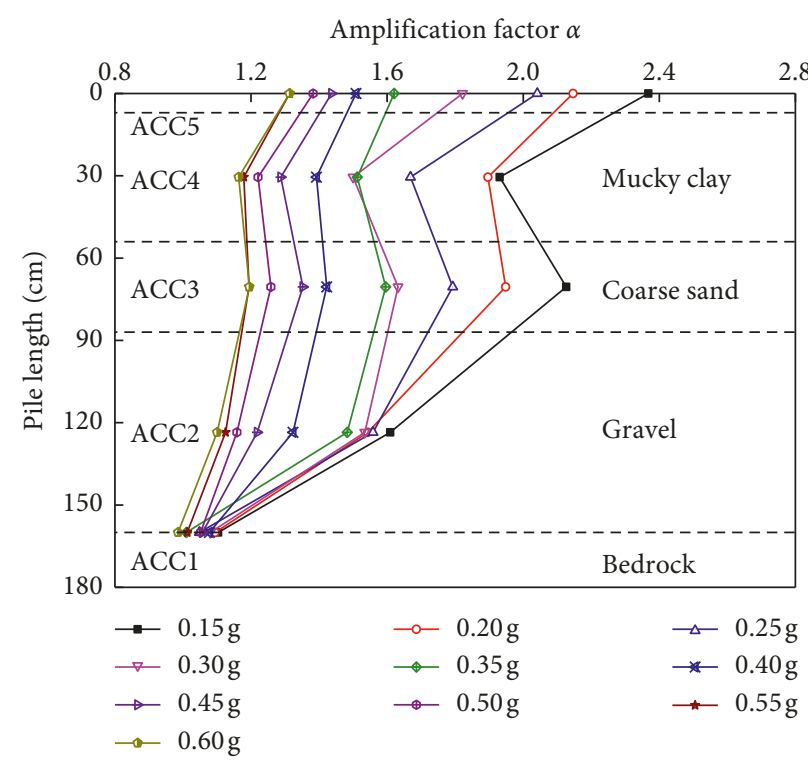

(b)

Figure 11: Pile acceleration response: (a) pile maximum acceleration of different seismic intensities and (b) amplification factor $\alpha$ of different seismic intensities.

length of the pile shows a similar variation law under different seismic intensities, and the acceleration and amplification factor increases from the bottom to the top of the pile for different seismic intensities. The distribution curves have turning point at the pile length $54 \mathrm{~cm}$ (ACC4) in the mucky clay layer, and the maximum acceleration and magnification factor of this point are smaller than those of the adjacent upper and lower soil layers, which may be related to the characteristics of the soil. Although the strength of each soil layer decreases from bottom to top, mucky clay has larger void ratio and water content than other soil layers.

The maximum acceleration at the bottom of the pile is close to the values of the seismic intensity, and the amplification factors at the bottom of the pile are less than 1.1. The maximum acceleration at the top of pile is larger, and the amplification factor is more than 1.3. It shows that under different seismic intensities, amplification effect of the gravel layer and coarse sand layer on the acceleration is evident, while the amplification effect of mucky clay on the acceleration is weakened, indicating that the weak soil layer can absorb a certain amount of seismic wave energy and the bedrock has a significant embedded effect on the pile.

As the seismic intensity increased from $0.15 \mathrm{~g}$ to $0.60 \mathrm{~g}$ with an increment of $0.05 \mathrm{~g}$, the maximum acceleration of the pile increased rapidly. From the bottom to top, the total increases of maximum acceleration of ACC1 ACC 5 were $257.3 \%, 173.6 \%, 124.9 \%, 141.1 \%$, and $121.8 \%$, respectively. On the contrary, the amplification factor decreases with the increase of seismic intensity and changes little when the seismic intensity is greater than $0.50 \mathrm{~g}$. It is deduced that with the increase of seismic intensity, the shear strain of soil increases, the stiffness modulus decreases, the damping ratio increases, and the amplification factor decreases. In addition, the foundation soil tends to become denser under continuous seismic vibration, which also reduces the seismic amplification effect to some extent.

Taking the pile top data as an example (Figure 12(e)), as the seismic intensity increases, the acceleration at the top of the pile increases linearly, whereas the amplification factor decreases. When the seismic intensity increases from $0.15 \mathrm{~g}$ to $0.60 \mathrm{~g}$, the maximum acceleration increases by $20.9 \%$, $43.7 \%, 53.9 \%, 59.7 \%, 69.9 \%, 82.0 \%, 94.7 \%, 103.4 \%$, and $121.8 \%$, respectively, and the amplification factor decreases by $20.9 \%, 43.7 \%, 53.9 \%, 59.7 \%, 69.9 \%, 82.0 \%, 94.7 \%$, $103.4 \%$, and $121.8 \%$, respectively.

When the seismic intensity is greater than $0.50 \mathrm{~g}$, the acceleration amplification factor at the top of the pile stabilizes at 1.32. This occurs because the ability of soil to transmit seismic waves decreases with increasing seismic intensity. The amplification factor of the pile decreased gradually due to the combination of lateral thrust and inertial forces of the rock or soil.

Time histories of pile acceleration for $0.35 \mathrm{~g}$ seismic intensity are plotted in Figure 13. As it can be observed in this figure, the peak of the acceleration at different depth lags behind from the bottom of the pile to the top of the pile and the amplitude of acceleration records present different laws. The acceleration amplitude at the bedrock near the bottom of the pile is close to the amplitude of the input seismic intensity. The acceleration record at the gravel layer (ACC2) shows significant amplification relative to the base motion because of its high shear strength. The amplitude of pile acceleration in the coarse sand layer is similar to that in the gravel layer. The shear strength of the upper mucky clay layer is low, but the water content is high and it is in a semifluid state, which has an obvious filtering effect on seismic waves. Therefore, the acceleration amplitude of the pile in this layer 


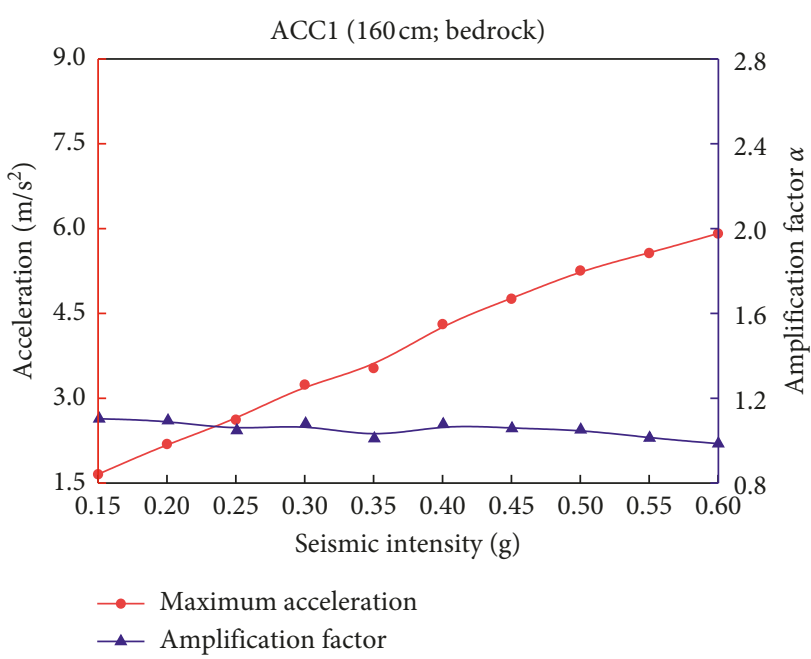

(a)

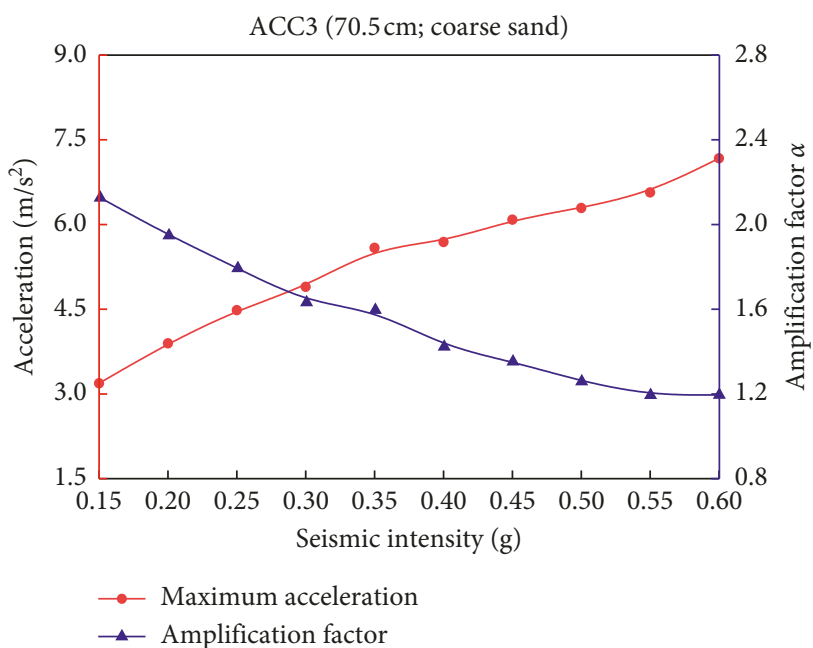

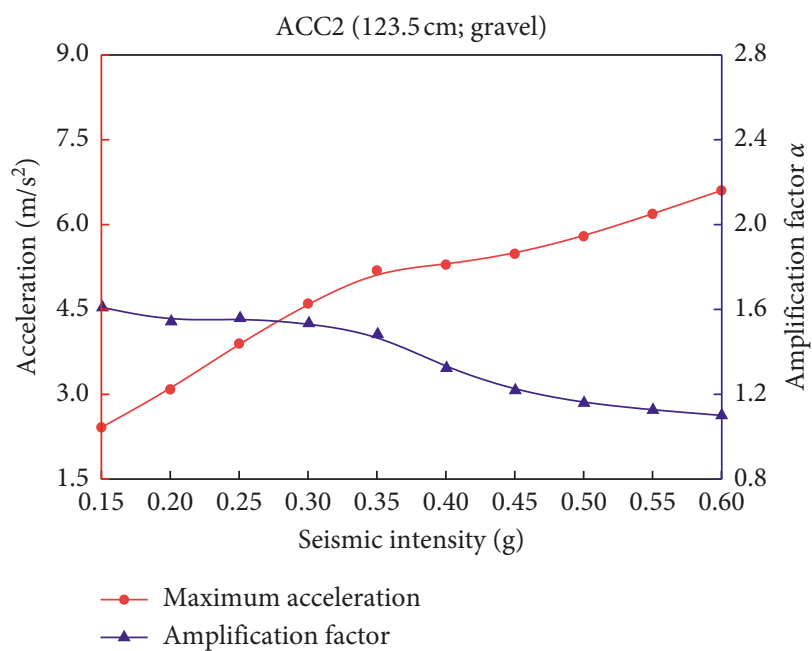

(b)

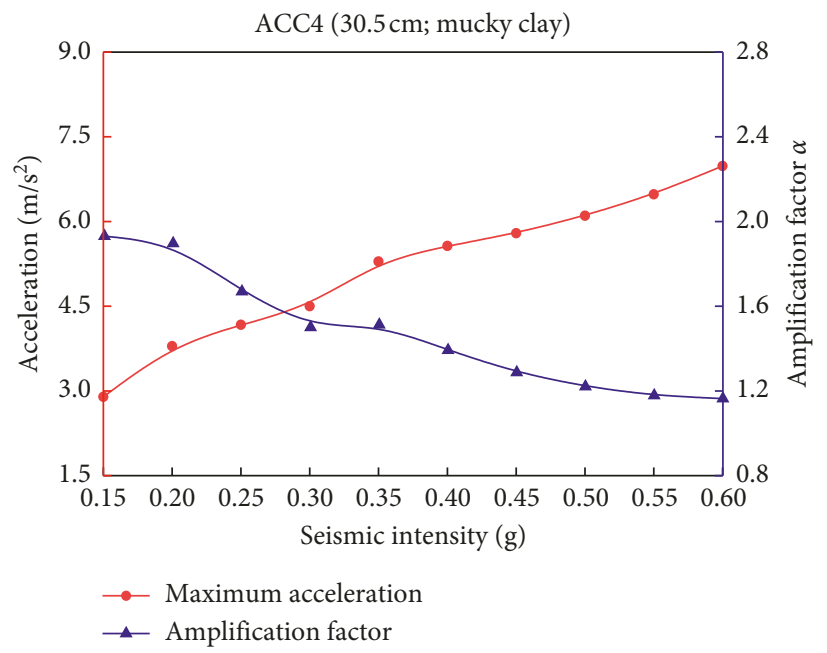

(d)

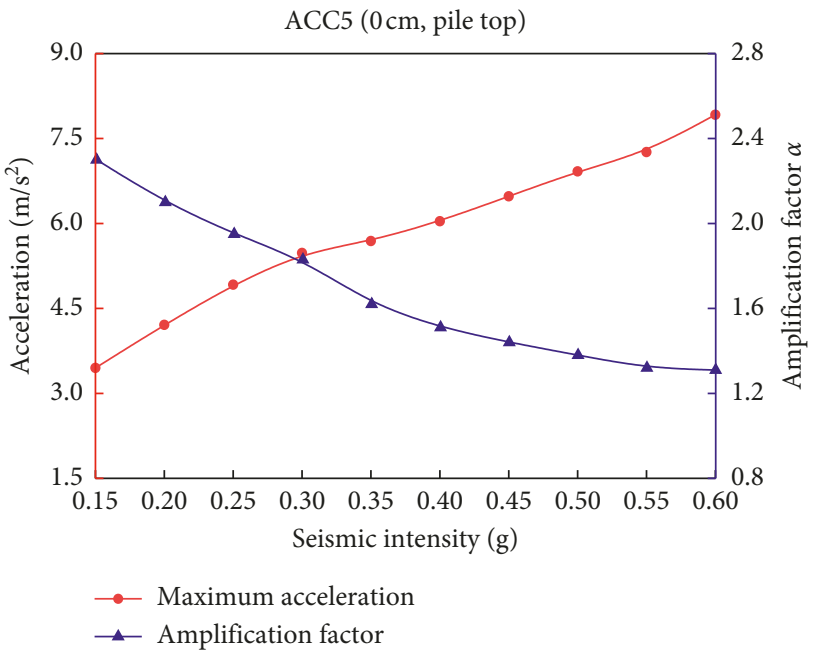

(e)

FIgURE 12: The maximum acceleration values and amplification factors of the pile: (a) ACC1; (b) ACC2; (c) ACC3; (d) ACC4; (e) ACC5.

is slightly reduced. In addition, each layer has a relatively small influence on the frequency of the seismic waves. The acceleration amplitude of the pile top is larger than that at other points and the acceleration frequency is lower than that at other points, which is related to the absence of soil constraints around the top of the pile. 


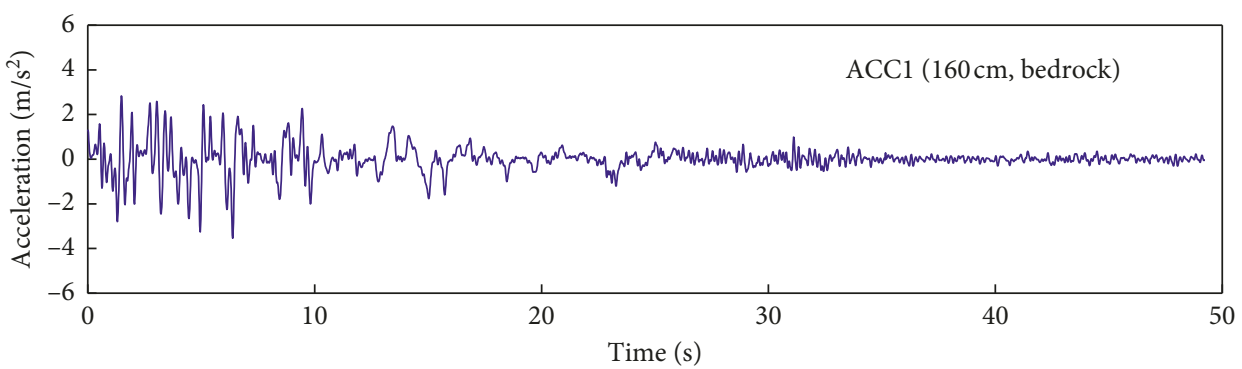

(a)

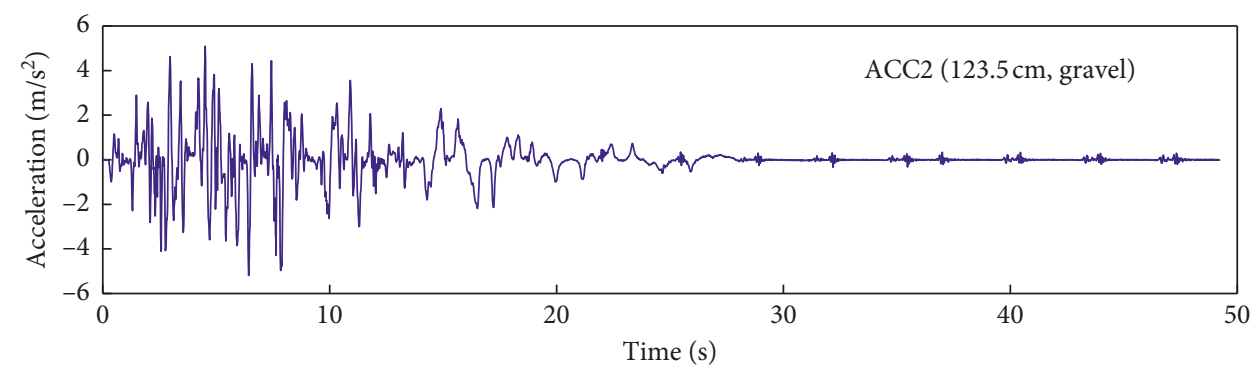

(b)

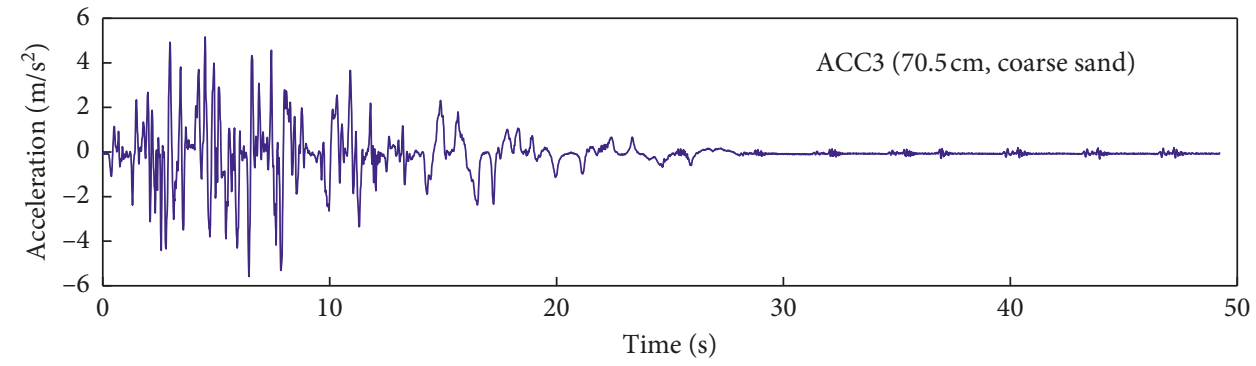

(c)

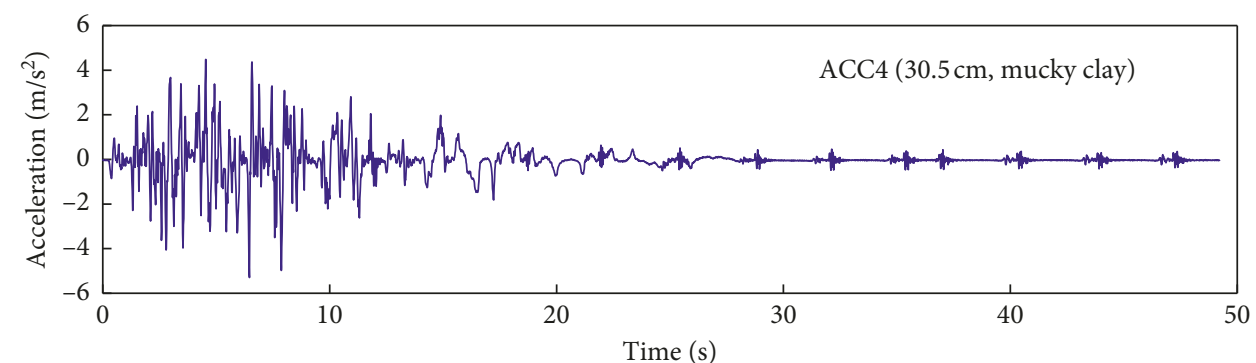

(d)

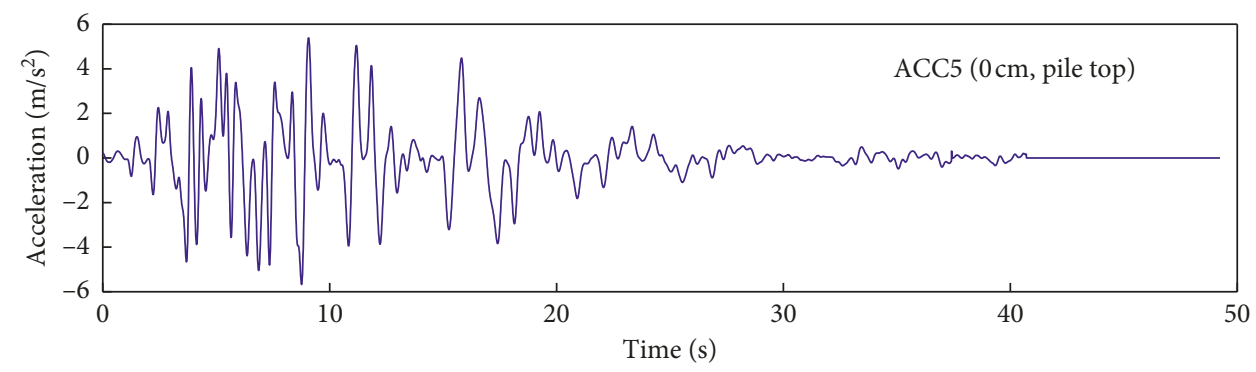

(e)

FIgURE 13: Time histories of pile acceleration for a seismic intensity of 0.35 g: (a) ACC1; (b) ACC2; (c) ACC3; (d) ACC4; (e) ACC5.

4.2. Horizontal Displacement of the Pile. Figure 14 shows the maximum relative horizontal displacements at the top of the pile for different seismic intensities from $0.15 \mathrm{~g}$ to $0.60 \mathrm{~g}$. As the seismic intensity increases, the maximum relative displacement at the top of the pile increases approximately linearly. The maximum relative displacement ranges from 


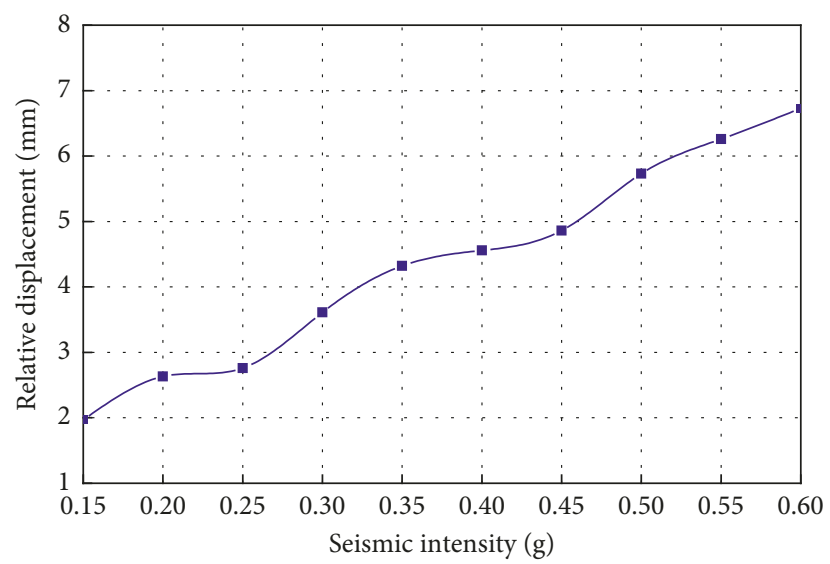

Figure 14: The maximum relative horizontal displacement at the top of the pile.

$1.97 \mathrm{~mm}$ to $6.73 \mathrm{~mm}$ as the input seismic intensity increases from $0.15 \mathrm{~g}$ to $0.60 \mathrm{~g}$.

4.3. Bending Moment of the Pile. In order to evaluate the bending resistance of the pile, the flexural capacity of the pile foundation was calculated according to the Specification of Design for Highway Reinforced Concrete and Prestressed Concrete Bridges and Culverts. (JTGD62-2018) [32], and the value was $168.54 \mathrm{kN} \cdot \mathrm{m}$ (shown in Figure 15). The bending moment of the pile is shown in Figure 16. As the seismic intensity increases, the maximum bending moments of the pile increase gradually. The maximum bending moment occurs at the boundary between the mucky clay layer and the coarse sand layer. There is also an increase in bending moment between the bedrock and the gravel. It shows that the bedrock has a strong embedded effect on the pile. At seismic intensities of $0.15 \mathrm{~g}-0.45 \mathrm{~g}$, the surplus flexural capacity of the pile foundation is $7.8 \% \sim 63.0 \%$, while at seismic intensities greater than $0.50 \mathrm{~g}$, the maximum bending moments of the pile exceeded the flexural capacity by $13.5 \%$ $81.2 \%$. The results indicate that the seismic design of the pile foundation in the Puqian Bridge is appropriate for the seismic fortification intensity of 8 degrees $(0.35 \mathrm{~g})$ :

$$
\begin{aligned}
M_{\mathrm{ud}} & =\frac{2}{3} f_{\mathrm{cd}} A r \frac{\sin ^{3} \pi \alpha}{\pi \alpha}+f_{\mathrm{sd}} A_{\mathrm{s}} r_{\mathrm{s}} \frac{\sin \pi \alpha+\sin \pi \alpha_{i}}{\pi}, \\
\alpha_{i} & =1.25-2 \alpha,
\end{aligned}
$$

where $M_{\mathrm{ud}}$ is the design value of flexural capacity of normal section $(\mathrm{kN} \cdot \mathrm{m}), A$ is the circular section area $(\mathrm{m}), A_{\mathrm{s}}$ is the cross-section area of all longitudinal ordinary steel bars $(\mathrm{m})$, $f_{\mathrm{cd}}$ is the design value of axial compressive strength of concrete $\left(\mathrm{kN} / \mathrm{m}^{2}\right), f_{\mathrm{sd}}$ is the design value of tensile strength of ordinary steel bar $\left(\mathrm{kN} / \mathrm{m}^{2}\right), r$ is the radius of a circular section $(\mathrm{m}), r_{\mathrm{s}}$ is the radius of the circumference, where the center of gravity of the longitudinal ordinary steel bar is located $(\mathrm{m}), \alpha$ is the ratio of rad to 2 pi corresponding to the area of concrete section in the compression zone, and $\alpha_{i}$ is the ratio of the section area of the longitudinal tension common steel bar to that of all longitudinal ordinary steel bars. When $\alpha_{i}$ is greater than $0.625, \alpha_{i}$ is 0 .
4.4. Analysis of Pile Damage. The Fourier spectrum of the pile is shown in Figure 17. The pile foundation was not damaged at a seismic intensity of $0.35 \mathrm{~g}$. Therefore, the damage of the pile foundation was analyzed only when the seismic intensity exceeded $0.35 \mathrm{~g}$.

The fundamental frequency of the pile foundation decreases as the seismic intensity increases; at a seismic intensity of $0.50 \mathrm{~g}$, the decrease in the fundamental frequency is $49.7 \%$ (Figure 18). Figure 18 shows that when the seismic intensity is greater than $0.50 \mathrm{~g}$, the pile foundation is being damaged, and the fundamental frequency of the pile foundation decreases slowly and tends to stabilize at $0.87 \mathrm{~Hz}$.

At the end of the test, the model pile was taken out and observed, and it was found that the cracks appeared near the junction of the top of the pile and cap and at the interface of the soft and hard soil and the bedrock, as shown in Figure 19.

4.5. Back-Calculaction of $p-y$ Curves. A $p-y$ curve defines the relationship between the lateral soil pressure and the pile displacement, which is widely used in the analysis of soil-pile interaction problems. In order to further study the interaction between the pile and the laterally spreading soil in this study, $p-y$ curves were back-calculated according to the recorded bending moment data. The relationship between the lateral soil pressure, the pile displacement, and the bending moment of the pile can be expressed by the following equations:

$$
\begin{aligned}
& p(z)=\frac{d^{2}(M(z))}{d z^{2}}, \\
& y(z)=\iint \frac{M(z)}{E I} d^{2} z .
\end{aligned}
$$

In the above equations, $M(z)$ is the bending moment of pile, $y(z)$ is the horizontal displacement of pile, and $p(z)$ is the lateral soil pressure on the pile due to lateral spreading, all at depth $z$. The lateral pressures should be determined by double differentiation of bending moment data; however, double differentiation procedure is associated with potential numerical errors. Different methods have been proposed to reduce or eliminate this error in order to obtain soil pressure 


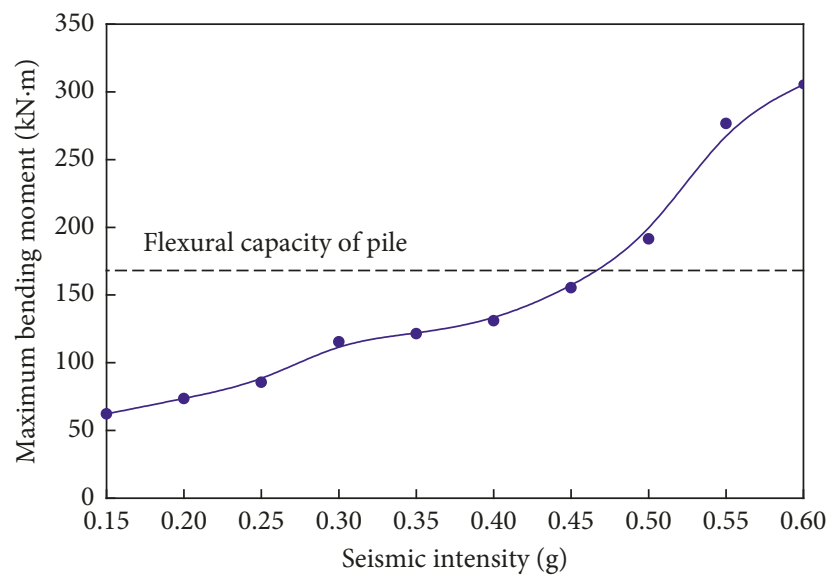

FIgURE 15: The maximum bending moments of the pile.

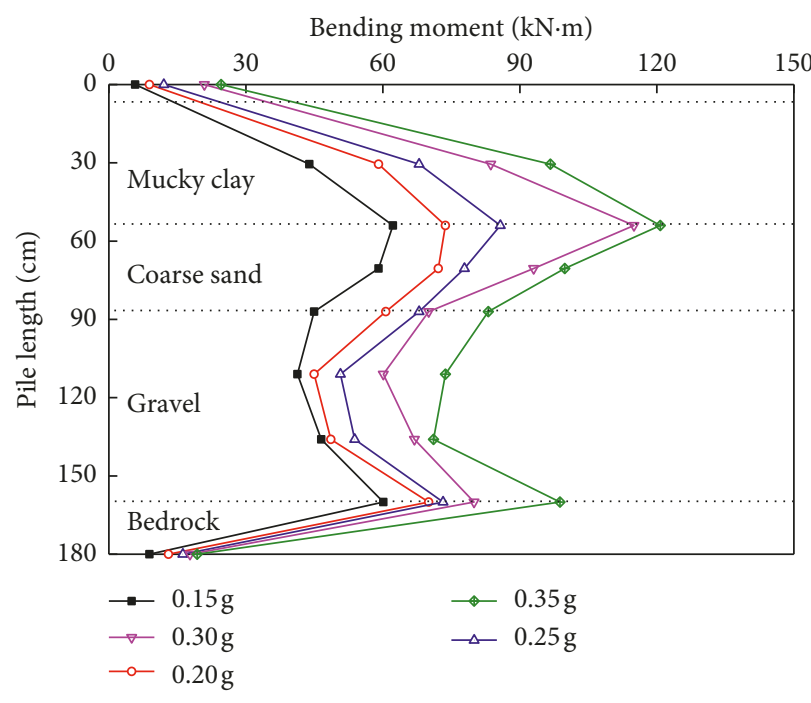

(a)

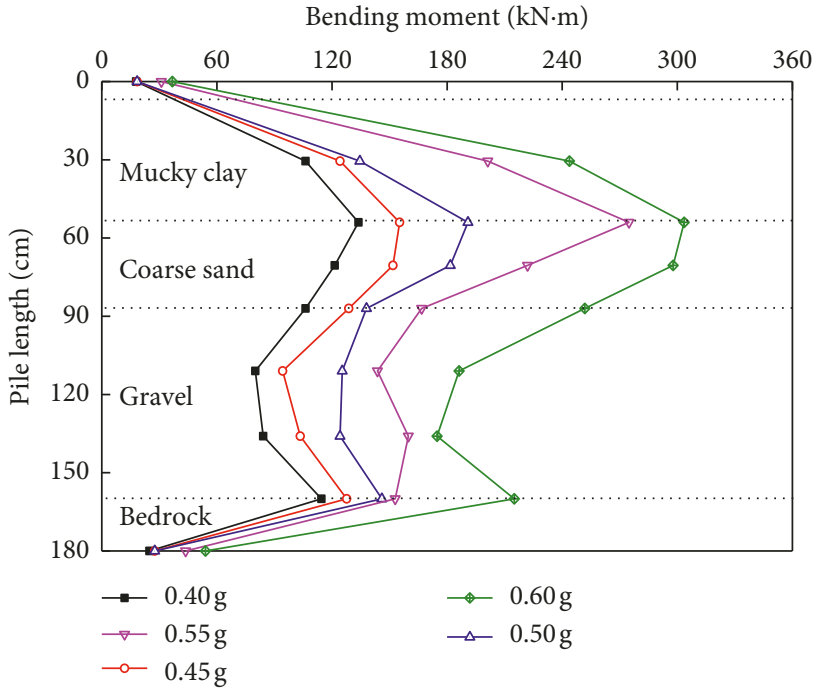

(b)

FIGURE 16: The bending moment of the pile for different seismic intensities: (a) seismic intensity of $0.15 \mathrm{~g}-0.35 \mathrm{~g}$; (b) seismic intensity of $0.40 \mathrm{~g}-0.60 \mathrm{~g}$.

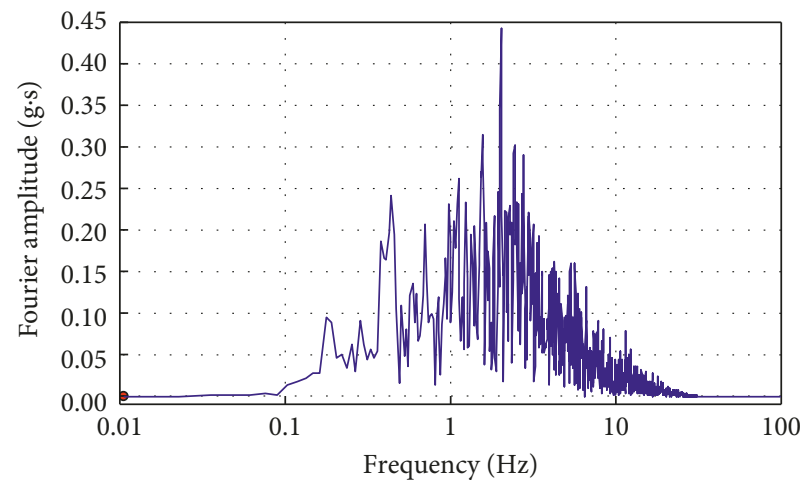

(a)

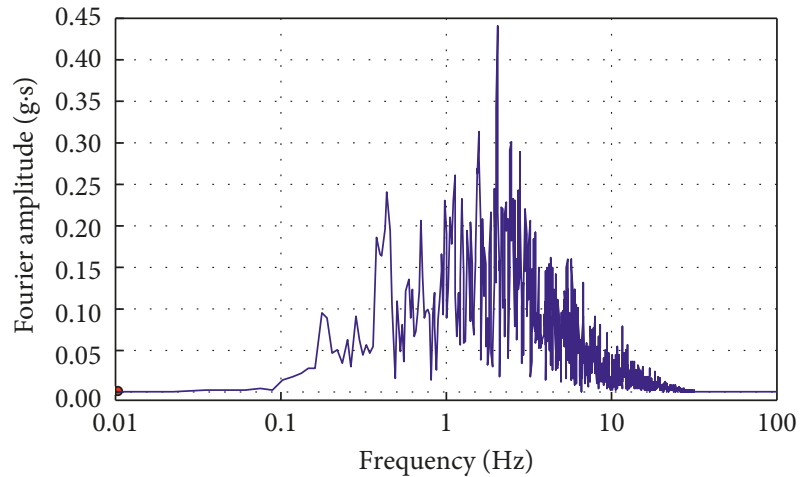

(b)

Figure 17: Continued. 


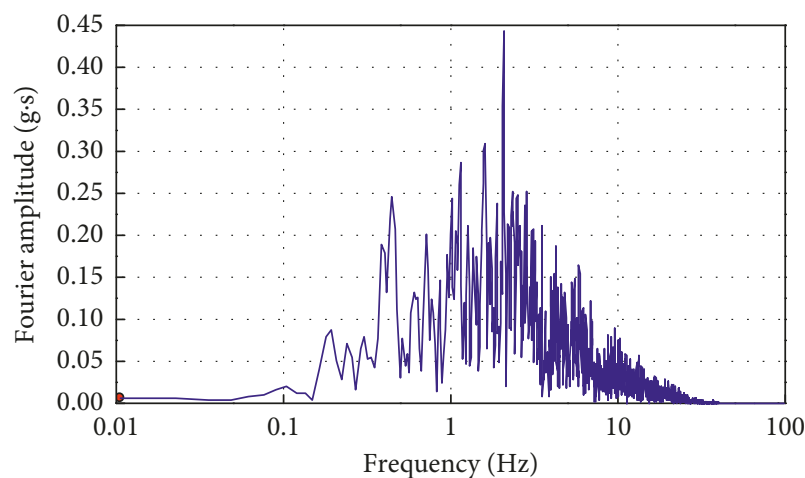

(c)

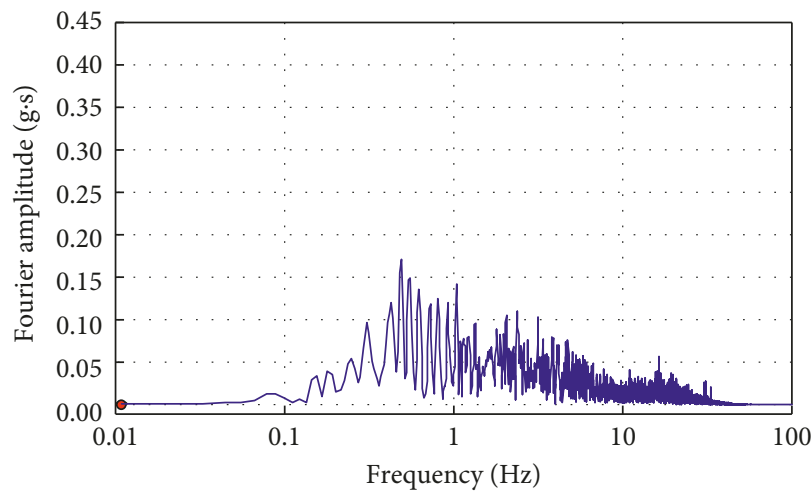

(e)

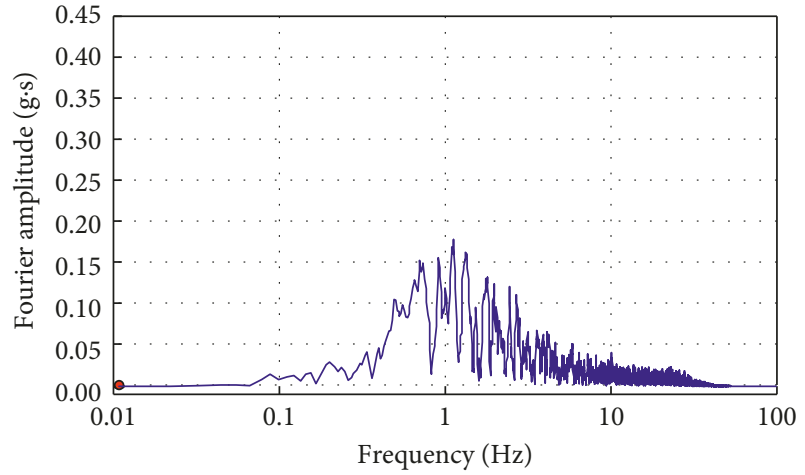

(d)

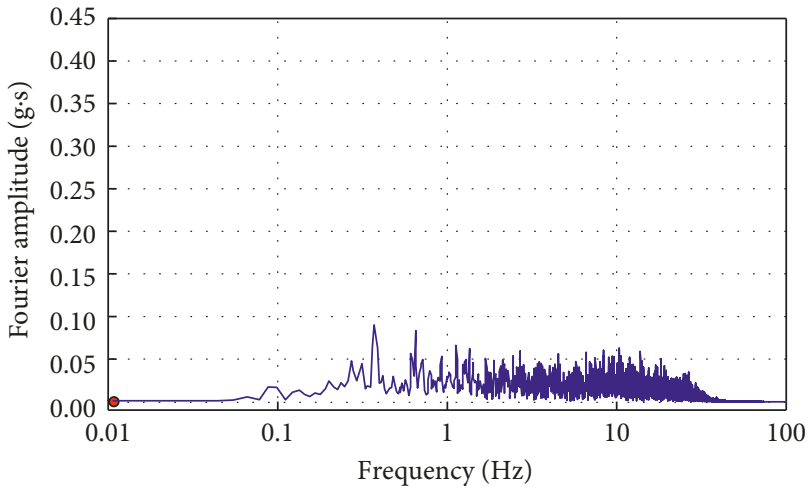

(f)

FIGURE 17: Fourier spectrum of the pile. (a) 0.35 g. (b) 0.40 g. (c) 0.45 g. (d) 0.50 g. (e) 0.55 g. (f) 0.60 g.

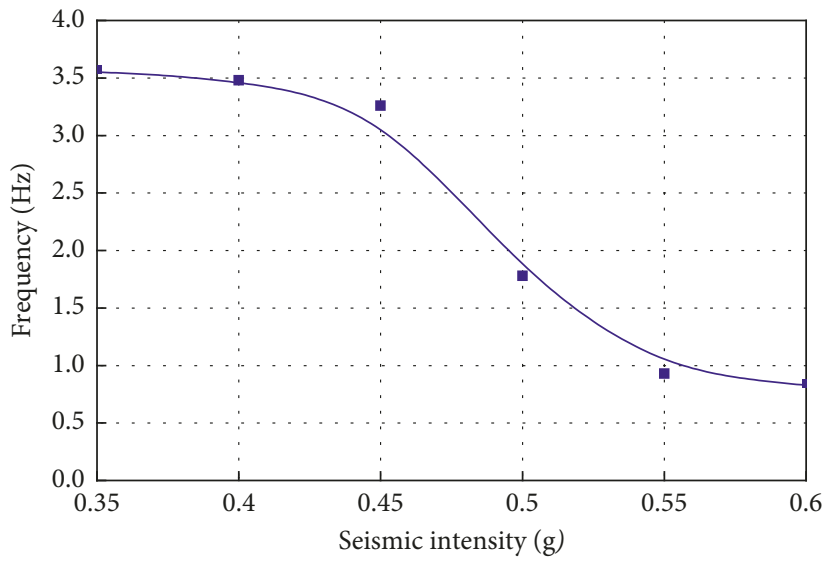

Figure 18: The fundamental frequency of the pile.

from discrete moment data points [33]. In this study, according to the principle of the weighted residual method proposed by Wilson et al. [34], the strain gauge attached to the pile body is taken as the separation node to divide the pile body into several elements. Let $f(z)$ be the bending moment function along the depth distribution, and the value of $f(z)$ at the node can be obtained from the strain gauges' recording data. Let $g(z)=f^{\prime}(z)$, so that $g(z)$ is a shear function along the depth distribution. According to the principle of the weighted residual method, the following equation is obtained:

$$
\int\left\{g(z)-f^{\prime \prime}(z)\right\} \cdot \psi(z) \mathrm{d} z=0
$$




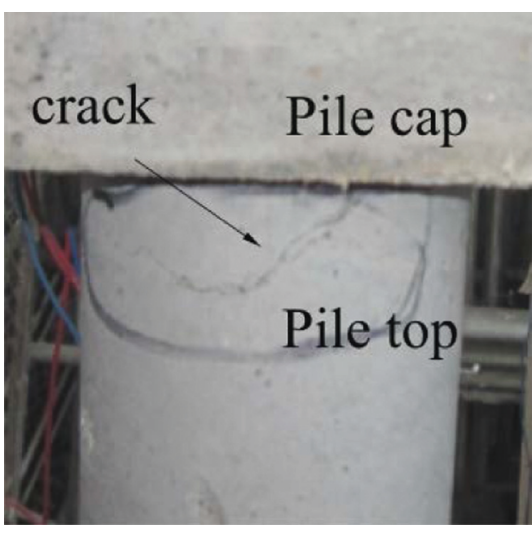

(a)

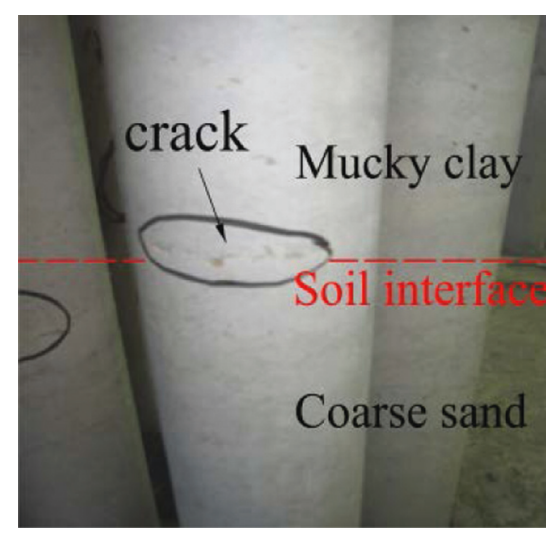

(b)

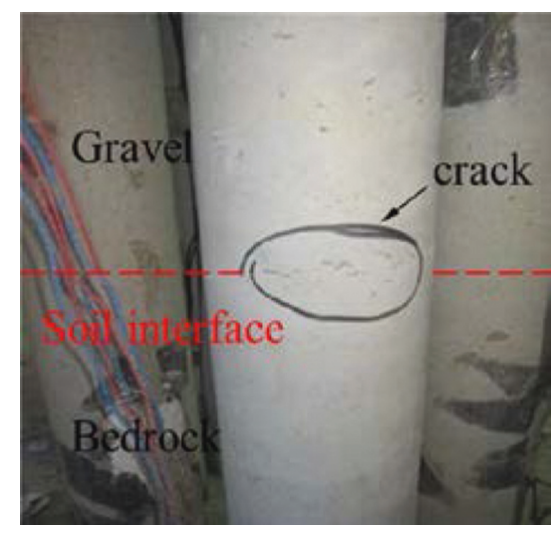

(c)

FIgURE 19: Pile crack damage: (a) the junction of the top of the pile and the cap; (b) soft-hard soil interface; (c) bedrock surface.

where $\psi(z)$ is the weight function, which is the basis function of the piecewise-linear interpolation method as follows:

$$
\begin{aligned}
& \psi_{0}(z)= \begin{cases}\frac{z-z_{1}}{z_{0}-z_{1}}, & z_{0} \leq z \leq z_{1}, \\
0, & z_{1} \leq z \leq z_{n},\end{cases} \\
& \psi_{i}(z)= \begin{cases}\frac{z-z_{i-1}}{z_{i}-z_{i-1}}, & z_{i-1} \leq z \leq z_{i}, \\
\frac{z-z_{j+1}}{z_{i}-z_{i+1}}, & z_{i} \leq z \leq z_{i+1}(i=1,2, \ldots, n-1), \\
0, & {\left[z_{0}, z_{n}\right]-\left[z_{i-1}, z_{i+1}\right],}\end{cases} \\
& \psi_{n}(z)= \begin{cases}\frac{z-z_{n-1}}{z_{0}-z_{1}}, & z_{n-1} \leq z \leq z_{n}, \\
0, & z_{0} \leq z \leq z_{n-1} .\end{cases}
\end{aligned}
$$

So, $f(z)$ and $g(z)$ can be written as

$$
\begin{aligned}
& f(z)=\sum_{i=0}^{n} f_{i} \cdot \psi_{i}(z) x, \\
& g(z)=\sum_{i=0}^{n} g_{i} \cdot \psi_{i}(z),
\end{aligned}
$$

where $i$ is the node number, $n$ is the total number of nodes, the strain gauge at the top of the pile is 0 node, $f_{i}$ is the measured bending moment at node $i$, and $g_{i}$ is the unknown shear force at node $i$. For different nodes, taking the corresponding weight function, the following equation can be obtained by using equation (6).

Node 0:

$$
\left(z_{1}-z_{0}\right)\left(g_{1}+2 g_{0}\right)=3\left(f_{1}-f_{0}\right) .
$$

Node $i$ :

$$
\left(z_{i}-z_{i-1}\right) g_{i-1}+2\left(z_{i+1}-z_{i-1}\right) g_{i}+\left(z_{i+1}-z_{i}\right) g_{i+1}=3\left(f_{i+1}-f_{i-1}\right) \text {. }
$$

Node $n$ :

$$
\left(z_{n}-z_{n-1}\right)\left(2 g_{n}+g_{n-1}\right)=3\left(f_{n}-f_{n-1}\right) .
$$

The above equations can be formed into a system of linear equations, which can be solved to obtain the shear force at each node. In this way, the shear distribution is also a piecewise-linear function. Again, by using the weighted margin method, the lateral soil pressure function $p(z)$ of the piecewise-linear distribution can be obtained. By applying the interpolation method to each element, the lateral soil pressure $p(z)$ at any depth of the pile can be obtained. From the above equations, it can be seen that the lateral soil pressure function of piecewise-linear distribution can be obtained directly according to the measured bending moment, and the numerical differential operation is avoided at the same time.

On the other hand, the pile displacement is obtained by the quadratic integral of the moment distribution function $M(z)$, see equation (5). Two boundary conditions are required, which are selected as the values of displacement and rotation angle at the base. Displacement and rotation angle at the base of the pile were considered to be zero as the pile was fixed at its base.

Under the input of 5010 seismic wave, the change of time history of each depth is relatively complex. Now, the period of $10.5 \mathrm{~s} \sim 11.0 \mathrm{~s}$ of input acceleration is selected for analysis. Back-calculated $p-y$ curves for the pile at various depths are provided in Figure 20.

Because the variation of 5010 seismic wave is complex, back-calculated $p-y$ curve is not regular and the complete hysteretic loop cannot be formed in a fixed time. When the seismic intensity increases, the lateral soil pressure and displacement of the pile at the same depth tend to increase. The increase of the lateral soil pressure is not only the result of the displacement increase, but also due to the inertia of vibrating soil layer. In this case, in addition to the action of the inertia force of the upper load, the pile may also be affected by the inertia force of the vibrating soil layer. The influence of seismic intensity on pile displacement is greater than that on lateral soil pressure. The latter is probably mainly affected by the properties of the soil around the pile. 


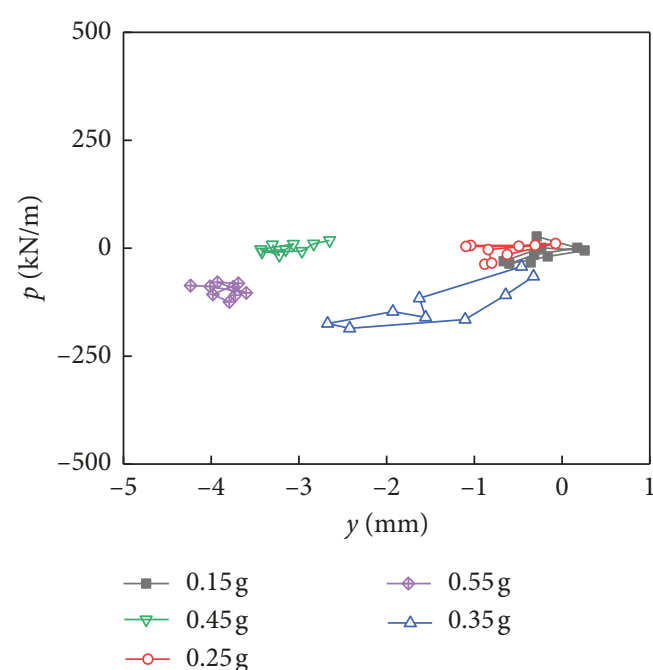

(a)

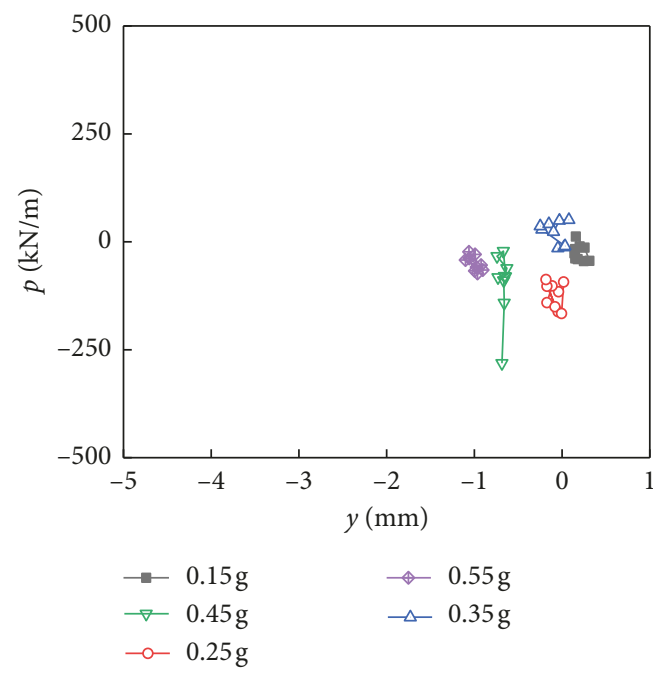

(c)

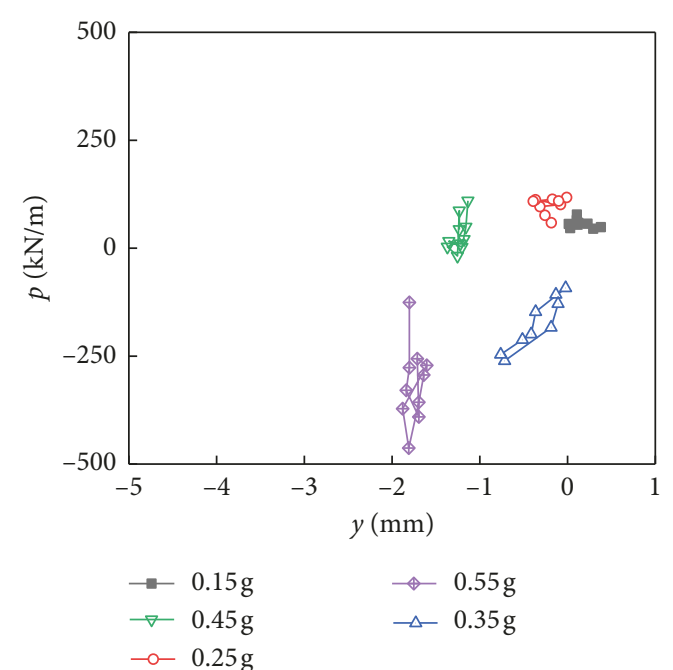

(b)

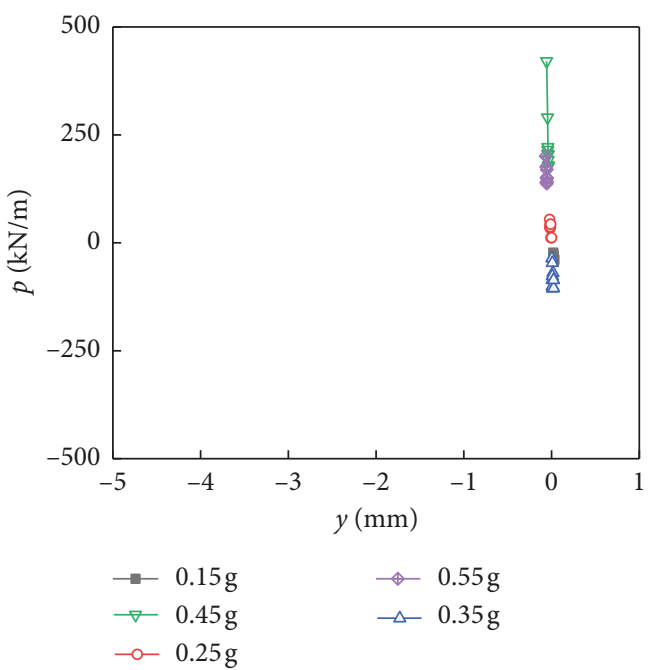

(d)

Figure 20: The $p-y$ hysteresis curves of the pile at different depths. (a) $23.5 \mathrm{~cm}$. (b) $63.5 \mathrm{~cm}$. (c) $104.0 \mathrm{~cm}$. (d) $153.0 \mathrm{~cm}$.

At the depth of $153 \mathrm{~cm}$, it can be seen that the displacement of the pile decreases obviously, indicating that the soil has a strong restraint effect on the pile and provides a greater resistance to the pile. For irregular seismic waves, the analysis of pile-soil interaction by $p-y$ curve seems to be inconvenient.

For the model test in this research, the law of similitude was applied. Due to the limitation to scale down the modulus and shear wave velocity of the sand specimen, the law of similitude was only partially fulfilled in this study. However, the strain ratio of the model and prototype was not affected and the use of the strain to characterize the pile behavior appeared to be reasonable. The responses and amplification of the model test appeared to reflect the behavior of the prototype pile under seismic loading conditions reasonably well.

\section{Conclusions}

Based on the artificial mass model and the pile-soil inertia interaction in the STT, the dynamic response of the pile foundation was analyzed for seismic intensity ranging from $0.15 \mathrm{~g}$ to $0.60 \mathrm{~g}$. The following conclusions were drawn.

(1) The peak acceleration of the pile increased along the length of the pile. The overburden layer amplified the seismic wave, and the acceleration amplification factor at the top of the pile gradually decreased with increasing seismic intensity. When the seismic intensity is greater than $0.50 \mathrm{~g}$, the acceleration amplification factor at the top of the pile stabilizes at 1.32 .

(2) The bending moment of the pile increased with the seismic intensity and exhibited a " 3 " shape along the pile length, reaching the maximum near the softhard soil interface and bedrock surface. In the seismic intensity range of $0.15 \mathrm{~g}$ to $0.45 \mathrm{~g}$, the maximum bending moment did not exceed the flexural capacity. The seismic design of the Puqian Bridge pile foundation is appropriate for the seismic fortification intensity of 8 degrees $(0.35 \mathrm{~g})$. 
(3) The fundamental frequency decreased with increasing seismic intensity. When the seismic intensity was greater than $0.50 \mathrm{~g}$, the fundamental frequency of the pile decreased significantly and the pile began to develop crack damage at the junction of the top of the pile and the cap, the soft-hard soil interface, and the bedrock surface.

(4) In the seismic design of bridge pile foundations, the pile should be embedded in stable bedrock at a certain depth and greater focus should be placed on the seismic design of the joint at the top of the pile and the cap, the soft-hard soil interface, and near the bedrock surface.

(5) With the increase of seismic intensity, the horizontal displacement of pile increases obviously, but the lateral soil pressure is irregular. The influence of seismic intensity on the horizontal displacement of the pile is greater than that on the lateral soil pressure.

\section{Data Availability}

The data used to support the findings of this study are available from the corresponding author upon request.

\section{Conflicts of Interest}

The authors declare that there are no conflicts of interest regarding the publication of this paper.

\section{Acknowledgments}

This study was financially supported by Transport Department of Hainan Provincial, China (No. HNZXY2015045R). The shaking table tests were performed at the National Center for Research in Earthquake Engineering (NCREE) and the help is highly appreciated. The authors would also like to express their great appreciation to Fengbin Yuan and Xiaoxiong Li for refining and finalizing the manuscript.

\section{References}

[1] S.-T. Song, C.-Y. Wang, and W.-H. Huang, "Earthquake damage potential and critical scour depth of bridges exposed to flood and seismic hazards under lateral seismic loads," Earthquake Engineering And Engineering Vibration, vol. 14, no. 4, pp. 579-594, 2015.

[2] G. Mylonakis, A. Nikolaou, and G. Gazetas, "Soil-pile-bridge seismic interaction: kinematic and inertial effects. Part I: soft soil," Earthquake Engineering \& Structural Dynamics, vol. 26, no. 3, pp. 337-359, 1997.

[3] S. M. Haeri, A. Kavand, I. Rahmani, and H. Torabi, "Response of a group of piles to liquefaction-induced lateral spreading by large scale shake table testing," Soil Dynamics and Earthquake Engineering, vol. 38, no. 7, pp. 25-45, 2012.

[4] L. A. Montejo, L. A. González-Román, and M. J. Kowalsky, "Seismic performance evaluation of reinforced concrete-filled steel tube pile/column bridge bents," Journal of Earthquake Engineering, vol. 16, no. 3, pp. 401-424, 2012.
[5] Y. E. Mostafa and M. H. E. Naggar, "Dynamic analysis of laterally loaded pile groups in sand and clay," Canadian Geotechnical Journal, vol. 39, no. 6, pp. 1358-1383, 2002.

[6] N. Naggar and G. Gazetas, "Dynamic pile-soil-pile interaction. Part II: lateral and seismic response," Earthquake Engineering \& Structural Dynamics, vol. 21, no. 2, pp. 145$162,2010$.

[7] R. W. Boulanger, C. J. Curras, B. L. Kutter, D. W. Wilson, and A. Abghari, "Seismic soil-pile-structure interaction experiments and analyses," Journal of Geotechnical and Geoenvironmental Engineering, vol. 125, no. 9, pp. 750-759, 1999.

[8] K. Hamayoon, Y. Morikawa, R. Oka, and F. Zhang, "3D dynamic finite element analyses and $1 \mathrm{~g}$ shaking table tests on seismic performance of existing group-pile foundation in partially improved grounds under dry condition," Soil Dynamics and Earthquake Engineering, vol. 90, pp. 196-210, 2016.

[9] H. Mroueh and I. Shahrour, "Three-dimensional finite element analysis of the interaction between tunneling and pile foundations," International Journal for Numerical \& Analytical Methods in Geomechanics, vol. 26, no. 3, pp. 217-230, 2010.

[10] R. Di Laora and E. Rovithis, "Kinematic bending of fixed-head piles in nonhomogeneous soil," Journal of Geotechnical and Geoenvironmental Engineering, vol. 141, no. 4, Article ID 04014126, 2015.

[11] H. Suzuki, K. Tokimatsu, and K. Tabata, "Factors affecting stress distribution of a $3 \times 3$ pile group in dry sand based on three-dimensional large shaking table tests," Soils and Foundations, vol. 54, no. 4, pp. 699-712, 2014.

[12] J. R. Dungca, J. Kuwano, A. Takahashi et al., "Shaking table tests on the lateral response of a pile buried in liquefied sand," Soil Dynamics and Earthquake Engineering, vol. 26, no. 2-4, pp. 287-295, 2006.

[13] S. Yao, K. Kobayashi, N. Yoshida, and H. Matsuo, "Interactive behavior of soil-pile-superstructure system in transient state to liquefaction by means of large shake table tests," Soil Dynamics and Earthquake Engineering, vol. 24, no. 5, pp. 397-409, 2004.

[14] R. Motamed and I. Towhata, "Shaking table model tests on pile groups behind quay walls subjected to lateral spreading," Journal of Geotechnical and Geoenvironmental Engineering, vol. 136, no. 3, pp. 477-489, 2010.

[15] M. Shirato, Y. Nonomura, J. Fukui, and S. Nakatani, "Largescale shake table experiment and numerical simulation on the nonlinear behavior of pile-groups subjected to large-scale earthquakes," Soils and Foundations, vol. 48, no. 3, pp. 375396, 2010.

[16] N. Ecemis, "Simulation of seismic liquefaction: 1-g model testing system and shaking table tests," European Journal of Environmental and Civil Engineering, vol. 17, no. 10, pp. 899-919, 2013.

[17] T. Chen, W. Ma, and J. Z. Wang, "Numerical analysis of ground motion effects in the loess regions of western China," Shock And Vibration, vol. 2017, Article ID 1484015, 9 pages, 2017.

[18] S. Kaneda, K. Hayashi, W. Hachimori, S. Tamura, and T. Saito, "Failure behavior of concrete pile and super-structure dynamic response as a result of soil liquefaction during earthquake," AIP Conference Proceedings, vol. 1892, no. 1, 2017.

[19] X. L. Zhang, Z. H. Wang, Z. W. Xu, and J. J. Sun, "Shaking table model tests on dynamic response of pile groups under liquefaction-induced large ground displacement," Engineering Mechanics, vol. 33, no. 5, 2016. 
[20] S. R. Pathak, A. N. Dalvi, and C. O'Neill, "Dynamic response based empirical liquefaction model," Cogent Geoscience, vol. 2, no. 1, p. 1190264, 2016.

[21] X. Shuang and M. Yuji, "Seismic response characteristics of a building supported by pile foundation in frozen soil based on shaking table test," Journal of Earthquake \& Tsunami, vol. 10, no. 2, Article ID 1640005, 2016.

[22] Z. Y. Tang, H. Ma, J. Guo, and Z. B. Li, "Effect of soil-structure interaction on seismic performance of long-span bridge tested by dynamic substructuring method," Shock And Vibration, vol. 2017, Article ID 4358081, 12 pages, 2017.

[23] M. Oliaei and S. Siabil, "Dynamic behavior of large-diameter piles considering liquefaction under clay layer," Scientia Iranica, vol. 24, no. 6, pp. 2665-2683, 2017.

[24] R. W. Boulanger, B. L. Kutter, and S. J. Brandenberg, "Pile foundations in liquefied and laterally spreading ground during earthquakes: centrifuge experiments \& analyses," Liquefaction, 2003.

[25] Ministry of Transport of the People's Republic of China, Specification of Seismic Design for Highway Engineering (JTG B02-2013), China Communications Press, Beijing, China, 2013.

[26] L. J. Yuan, X. S. Liu, X. G. Wang, Z. Q. Yang, and Y. S. Yang, "Analytic solution of dynamic characteristics and responses of soil-box model for shaking table tests," Chinese Journal of Geotechnical Engineering, vol. 34, no. 6, pp. 1038-1042, 2012.

[27] S. Iai, T. Tobita, and T. Nakahara, "Generalised scaling relations for dynamic centrifuge tests," Géotechnique, vol. 55, no. 5, pp. 355-362, 2005.

[28] D. Pitilakis, M. Dietz, D. M. Wood, D. Clouteau, and A. Modaressi, "Numerical simulation of dynamic soilstructure interaction in shaking table testing," Soil Dynamics and Earthquake Engineering, vol. 28, no. 6, pp. 453-467, 2008.

[29] M. Kumar and S. S. Mishra, "Study of seismic response characteristics of building frame models using shake table test and considering soil-structure interaction," Asian Journal of Civil Engineering, vol. 20, no. 3, pp. 409-419, 2019.

[30] M. Z. Zhang, "Study of similitude laws for shaking table tests," Earthquake Engineering and Engineering Vibration, vol. 17, no. 2, pp. 52-58, 1997.

[31] W. Huang, "Study on the analogy between scale models with less ballast and their prototypes under shaking table test," Earthquake Engineering \& Engineering Vibration, vol. 14, no. 4, pp. 64-71, 1994.

[32] Ministry of Transport of the People's Republic of China, Specification of Design for Highway Reinforced Concrete and Prestressed Concrete Bridges and Culverts (JTGD62-2004), China Communications Press, Beijing, China, 2018.

[33] C. L. Wang, J. H. Wang, and S. L. Feng, "Analysis on $p-y$ curves of soil-pile interaction in liquefied soils," Chinese Journal of Geotechnical Engineering, vol. 29, no. 10, pp. 1500-1505, 2007.

[34] D. W. Wilson, R. W. Boulanger, and B. L. Kutter, "Observed seismic lateral resistance of liquefying sand," Journal of Geotechnical and Geoenvironmental Engineering, vol. 126, no. 10, pp. 898-906, 2000. 


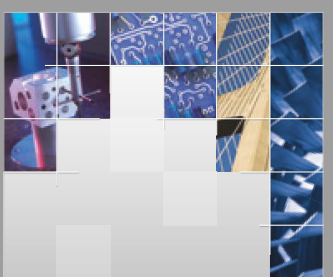

\section{Enfincering}
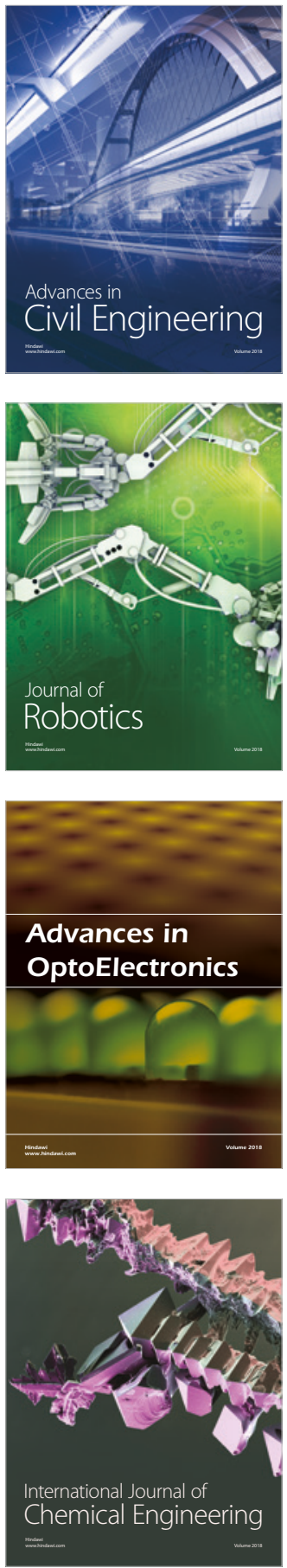

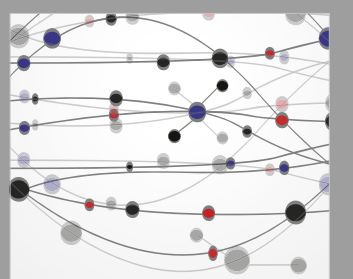

\section{Rotating \\ Machinery}

The Scientific World Journal

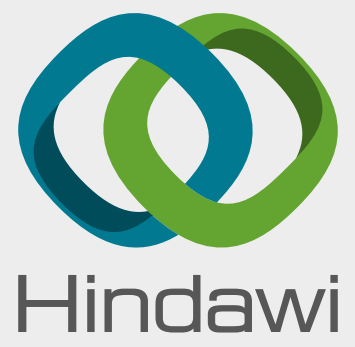

Submit your manuscripts at

www.hindawi.com
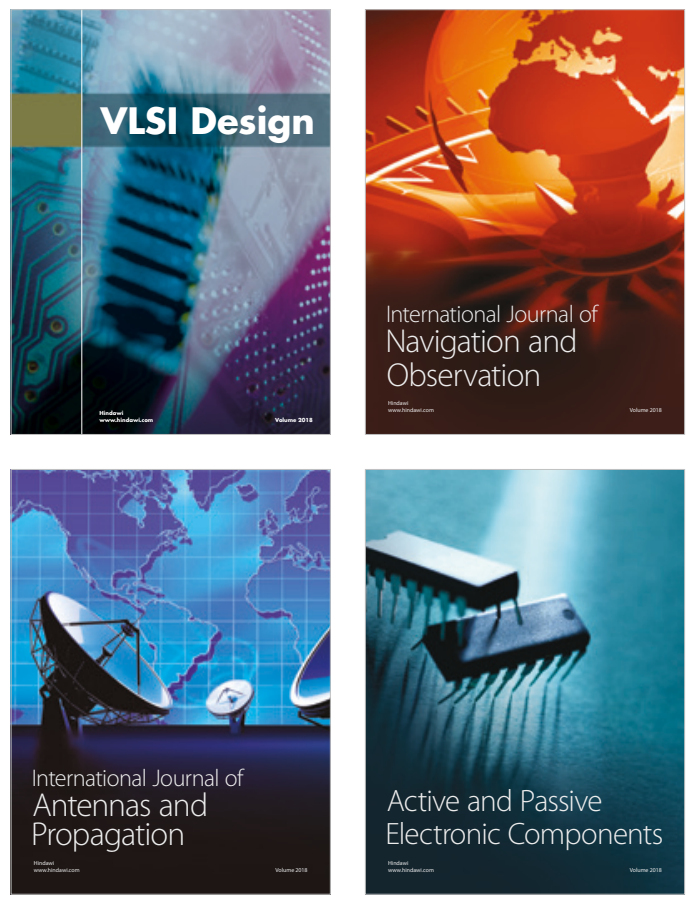
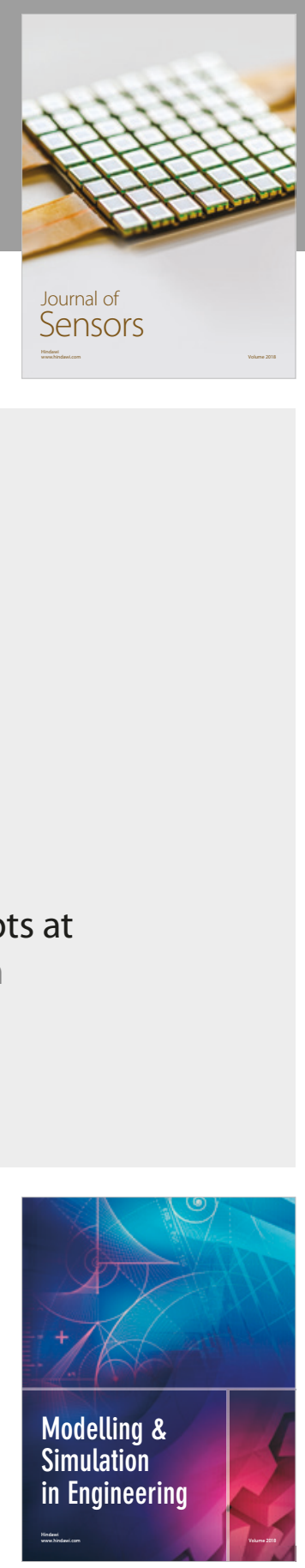

\section{Advances \\ Multimedia}
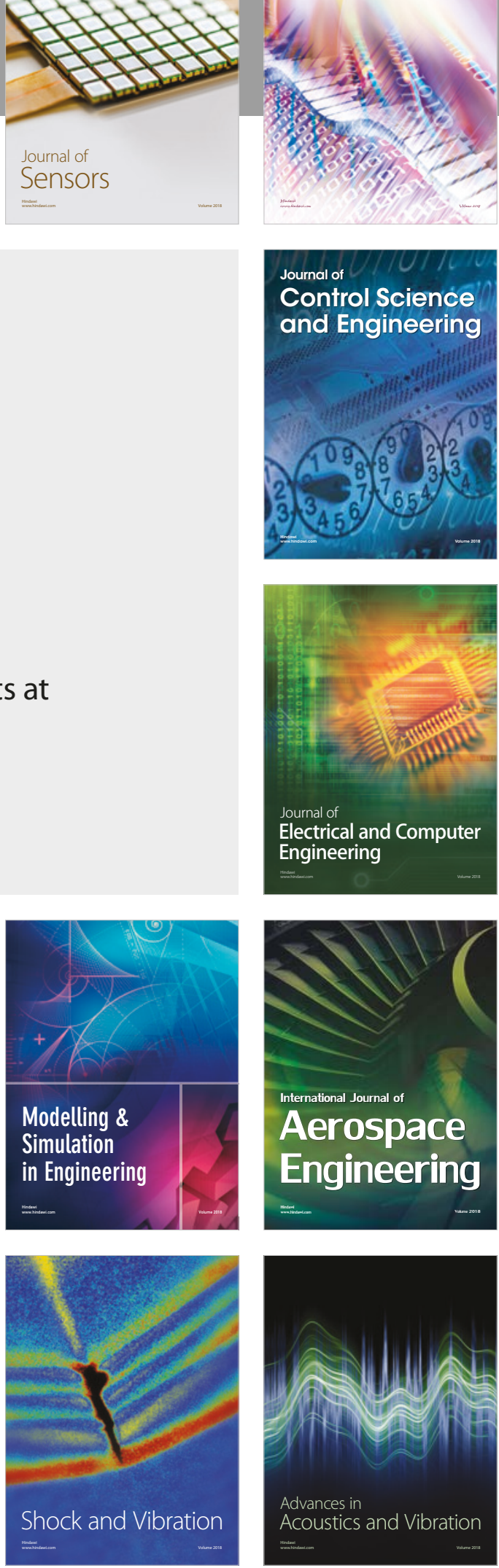